THE LIMITS OF ARBITRAGE AND STOCK MISPRICING: EVIDENCE FROM DECOMPOSING THE MARKET TO BOOK RATIO

Naji Mohammad AlShammasi, B.S, MSF

Dissertation Prepared for the Degree of

DOCTOR OF PHILOSOPHY

UNIVERSITY OF NORTH TEXAS

December 2015

APPROVED:

Niranjan Tripathy, Committee Chair

Mazhar Siddiqi, Committee Member

Ian Liu, Committee Member

Margie Tieslau, Minor Professor

Marcia Staff, Chair of the Department of Finance, Insurance, Real Estate and Law

Marilyn Wiley, Dean of the College of Business

Costas Tsatsoulis, Dean of the Toulouse Graduate School 
AlShammasi, Naji Mohammad. The Limits of Arbitrage and Stock Mispricing: Evidence from Decomposing the Market to Book Ratio. Doctor of Philosophy (Finance), December 2015, 72 pp., 12 tables, 1 figure, references, 94 titles.

The purpose of this paper is to investigate the effect of the "limits of arbitrage" on securities mispricing. Specifically, I investigate the effect of the availability of substitutes and financial constraints on stock mispricing. . In addition, this study investigates the difference in the limits of arbitrage between stocks that are included in the Standard \& Poor's 500 index (S\&P 500 hereafter) and non-S\&P 500 stocks. I expect S\&P 500 stocks to have, on average, lower levels of the limits of arbitrage, in the sense that it will lead to lower mispricing for these stocks, relative to non-S\&P 500 stocks. I also examine if the lower mispricing can be attributed to their lower limits of arbitrage.

Modern finance theory and efficient market hypothesis suggest that security prices, at equilibrium, should reflect their fundamental value. If the market price deviates from the intrinsic value, then a risk-free profit opportunity has emerged and arbitrageurs will eliminate mispricing and equilibrium is restored. This arbitrage process is characterized by large number of arbitrageurs which have infinite access to capital. However, a better description of reality is that there are few numbers of arbitrageurs to the extent that they are highly specialized; and they have limited access to capital. Under these condition arbitrage is no more a risk-free activity and can be limited by several factors such as arbitrage risk and transaction costs.

Other factors that are discussed in the literature are availability of substitutes and financial constraints. The former arises as a result of the specialization of arbitrageurs in the market in which they operate, while the latter arises as a result of the separation between arbitrageurs and capital. In this dissertation, I develop a measure of the availability of substitutes that is based on the 
propensity scores obtained from propensity score matching technique. In addition, I use the absolute value of skewness of returns as a proxy of financial constraints.

Previous studies used the limits of arbitrage framework to explain pricing puzzles such as the closed-end fund discounts. However, closed-end fund discounts are highly affected by uncertainty of managerial ability and agency problems. This study overcomes this problem by studying the effect of limits of arbitrage on publicly traded securities. The results show that there is a significant relationship between proxies of limits of arbitrage and firm specific mispricing. More importantly, empirical results indicate that stocks that have no close substitutes have higher mispricing. In addition, stocks that have high skewness show higher mispricing.

Subsequent studies show that the S\&P 500 stocks have different levels of liquidity, analysts' coverage and volatility. These characteristics affect the ability of arbitrageurs to eliminate mispricing. Preliminary univariate tests show that S\&P 500 stocks have, on average, lower mispricing and limits of arbitrage relative to non-S\&P 500 stocks. In addition, the multivariate test shows that S\&P 500 members have, on average, lower mispricing relative to non-S\&P 500 stocks. 


\section{Copyright 2015}

\section{by}

Naji Mohammad AlShammasi 


\section{ACKNOWLEDGMENTS}

I would like to seize this opportunity to express my gratitude to the people that helped me completing my doctoral study. First I want to thank Dr. Niranjan Tripathy, my committee chair whose guidance, patience, and support made this dissertation possible. Also, I want to extend my appreciation to the other committee members: Dr. Mazhar Siddiqi and Dr. Ian Liu for their advice that helped in shaping this study. A special and warm thanks to my minor professor Dr. Margie Tieslaue her valuable suggestions that tremendously facilitated writing this dissertation.

I am also indebted to my dear friend and officemate, Adel Al-Momen, who helped immensely in programming and writing codes for this dissertation. In addition, my sincere thanks to all my classmates especially Mujtaba Zia whom with I shared a lot of moments, memories, and sleepless nights studying together. The program would have been so different without you.

A special and deep gratitude to Dr. F.J. Seyyed whose mentorship and advice guided me through the way in my undergraduate studies and beyond.

To my father, Mohammad Al-Shammasi, you are my role model and your words have been and always will be the torch that lightens my way. Today I can tell you that your dream is becoming true. To my mother, Fatima Al-Buraiky, you taught me a lot through the years and it turned out that I'm not a bad student after all. To my brother and sisters, thank you deeply from the bottom of my heart for your love and support.

To my wife, Amel Al-Yousef, this journey could not be done without you. Your effort, patience, and unconditional love were the greatest help and motivation through the years. To my kids, Shams and Mohammad, I love you so much and I'm sorry for all the time I didn't spend with you. I promise I will have more time to play with you in the future. 


\section{TABLE OF CONTENTS}

Page

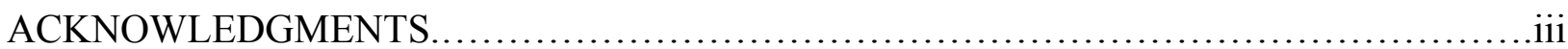

LIST OF TABLES AND FIGURES ..........................................................

Chapters

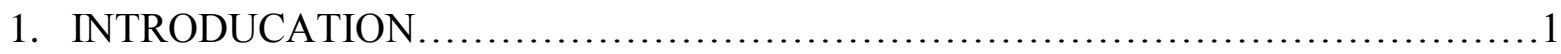

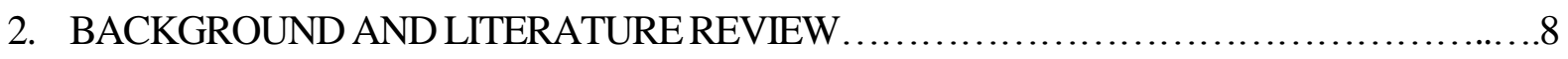

2.1 The Limits of Arbitrage and Stock Mispricing.........................................

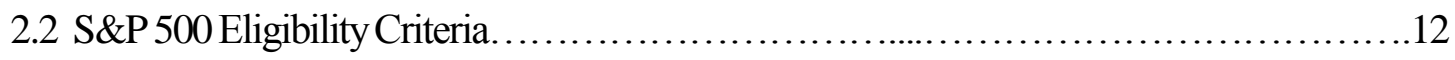

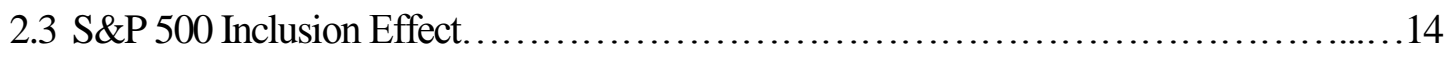

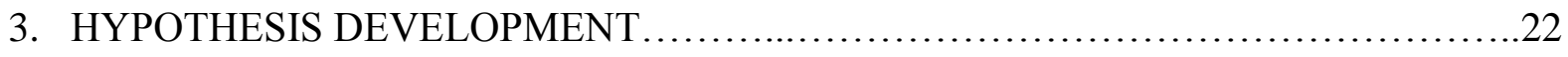

3.1 Availability of Substitutes and Financial Constraints Hypotheses................22

3.2 Index Membership and Stock Mispricing Hypotheses..........................23

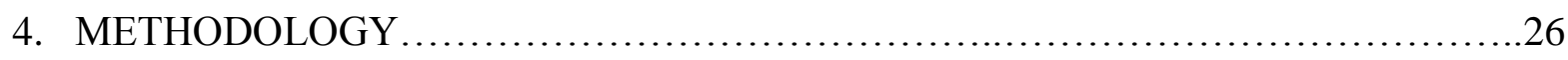

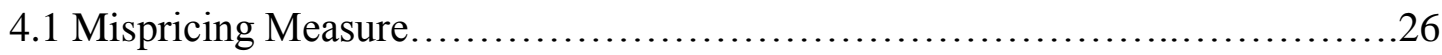

4.2 Availability of Substitutes and Financial Constraint Measures.......................30

4.3 Empirical Model and Independent Variables..................................33

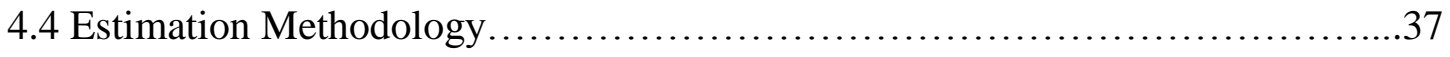


5. DATA AND EMPIRICAL RESULTS

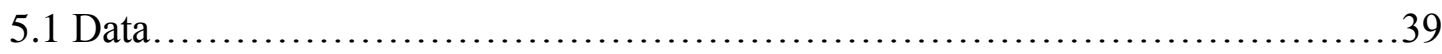

5.2 Descriptive Statistics and Empirical Results............................... 39



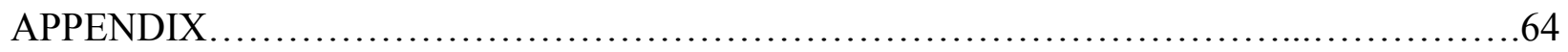

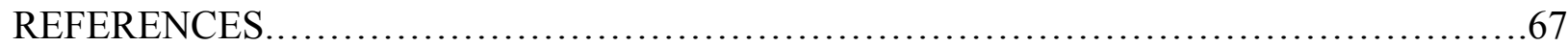




\section{LIST OF TABLES AND FIGURES}

Page

FIGURES

1. Average Annual Mispricing 1982-2012....................................50

\section{TABLES}

1. Time Series Average Conditional Regression Coefficients (Rhodel Kropf et al. (2005)

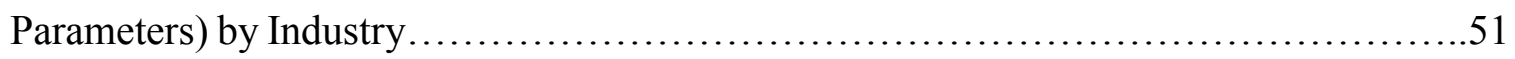

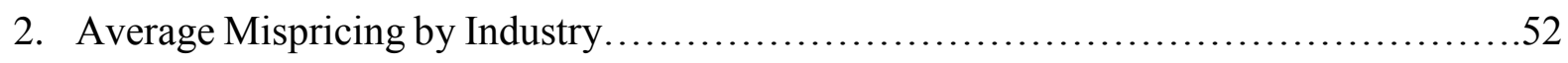

3. Time Series Average of the Logit Regression Coefficients by Industry $\ldots \ldots \ldots \ldots \ldots \ldots . . .53$

4. Summary Statistics for the Full Sample........................................54

5. Time Series Average of Variables by Industry................................55

6. Mispricing and Limits of Arbitrage Regression.................................56

7. Summary Statistics of Non-S\&P 500 Stocks and S\&P 500 Stocks...................57

8. Non-S\&P 500 versus S\&P 500 Members: Comparison of Mean and Median of Dependent Variables............................................................... 58

9. Non-S\&P 500 versus S\&P 500 Members: Comparison of Mean and Median of the Absolute Value of Mispricing..............................................59

10. Magnitude of Mispricing Regression with S\&P 500 Dummies.....................60

11. Pearson Correlation Matrix for Independent Variables............................62

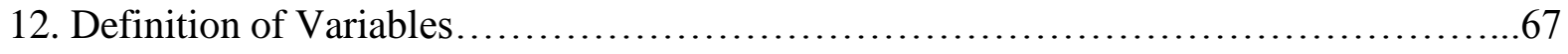




\section{CHAPTER 1}

\section{INTRODUCTION}

The purpose of this paper is to investigate the effect of the "limits of arbitrage" on securities mispricing of publicly traded stocks. There are many factors that may limit the ability of arbitrageurs to eliminate mispricing. These factors include: idiosyncratic volatility, information uncertainty, transaction costs, and availability of substitutes. In order to measure securities mispricing, I decompose the M/B ratio into three components: firm specific mispricing, sector mispricing, and a long-term growth component (Rhodes-Kropf et al. 2005). I use the first component as a measure of stock mispricing. Moreover, I develop a new measure of the availability of substitutes for stocks. This measure is calculated based on the fitted values (propensity scores) of the propensity score matching technique. Moreover, I test for the effect of financial constraint (measured by skewness of returns) on securities mispricing.

In addition, this study investigates the difference in the limits of arbitrage between stocks that are included in the Standard \& Poor's 500 index (S\&P 500 hereafter) and non-S\&P 500 stocks. I expect S\&P 500 stocks to have, on average, lower levels of the limits of arbitrage, in the sense that it will lead to lower mispricing for these stocks, relative to non-S\&P 500 stocks. I also examine if the lower mispricing can be attributed to their lower limits of arbitrage.

Efficient Market Hypothesis (EMH) suggests that security prices fully reflect the available information (Fama, 1970). This efficient market paradigm relies on several assumptions. First, market participants are assumed to be rational and maximize their expected utility of wealth. Second, markets are frictionless and there are no transaction costs. Third, information is costless and available to everybody. Finally, investors are price takers in the sense that securities are traded in a perfectly competitive market. These assumptions imply market participants value securities 
rationally to the extent that security prices reflect their fundamental value. In addition, investors cannot consistently earn a positive abnormal return above the equilibrium required rate of return.

Modern finance theory suggests that in an efficient capital market, the required rate of return on a stock is determined by a relevant risk factor, CAPM (Sharpe, 1964), or multiple risk factors, APT (e.g. Ross, 1976; and Fama and French, 1993, 1996). Therefore, if irrational investors drive the price of a security away from its fundamental value, rational market participants, or "arbitrageurs", will explore this opportunity by creating an arbitrage portfolio that replicates the payoff of the mispriced security (Friedman, 1953). The arbitrage process described is a standard textbook arbitrage in which the arbitrageur identifies an overvalued (undervalued) security and then he shorts (buys) it and uses the proceeds to buy (short) a similar security or a portfolio with similar risk characteristics. As this activity continues, mispricing will be eliminated and equilibrium will be restored. This process under this framework has three main characteristics: arbitrage is costless, arbitrageurs have infinite access to capital, and the arbitrage process is riskfree.

However, Grossman and Stiglitz (1980) show that if information is costly to acquire, then market participants will collect information until the marginal benefit of acquiring information is equal to the marginal cost. At this point, other market participants find no incentive to collect extra information and they will observe prices to infer information because prices reflect valuable collected information. Therefore, prices do not reflect all available information, but instead they reflect collected information. As a result, information asymmetry and costly information can cause prices to deviate from their fundamental value and mispricing exists.

Many other theoretical and empirical studies also have shown that if arbitrage is limited, securities mispricing can persist even if market participants are rational utility maximizers. Shleifer 
and Vishny (1997) argue that textbook arbitrage differs from real life arbitrage activity. They argue, in contrast to Sharpe's (1964) CAPM and Ross's (1976) APT, that arbitrageurs are highly specialized and have limited access to capital. Specialization implies under-diversification which makes the arbitrageur subject to idiosyncratic risk and the risk that prices do not converge to fair value. In addition, specialization limits the ability of arbitrageurs to locate mispriced securities with same level of risk in other markets (sectors) in which they do not have expertise.

The separation between expertise and capital creates an agency problem. Arbitrageurs' decisions will be based on their knowledge and expertise in the industry in which they are operating. They will identify mispriced securities and obtain funding from capital providers. Capital providers, on the other hand, evaluate the arbitrage portfolio based on its past performance and current value. As a result, they might force the arbitrageur to liquidate the arbitrage portfolio before the maturity of his trade. Therefore, arbitrage is more present in markets that have higher liquidity, lower transaction costs, lower volatility; and arbitrage becomes more effective when arbitrageurs are not financially constrained. These criteria lower the risk faced by arbitrageurs and increase the probability that they will realize their profits quickly.

Shleifer and Summers (1990) indicate that arbitrageurs trades keep the relative prices of securities in line with their fundamentals for classes of securities with close substitutes. However, for security classes that do not have close substitutes or close substitutes portfolios, arbitrageurs cannot create a riskless hedge for mispriced securities. Therefore, given that there are few numbers of arbitrageurs, arbitrage is no more a risk-free activity.

Several studies use of the limits of arbitrage or the arbitrage costs framework to investigate empirical pricing puzzles such as the closed-end fund discount. A closed-end fund is a corporation that holds an observable diversified portfolio. However, the value of the portfolio differs from the 
value of its components that are traded in the open market. Pontiff (1996) examines the effect of the limits of arbitrage on a sample of 52 closed-end fund discount. His results suggest that the absolute value of the premium/discount is positively related to idiosyncratic volatility and transaction costs which indicate that mispricing is a result of limited arbitrage and arbitrage costs. These results, however, can be highly affected by managerial ability and agency problems in the context of delegated portfolio management.

Mitchell et al. (2002) examine a sample of 82 "negative stub values". A negative stub value is a situation in which the market value of a publicly traded subsidiary is greater than the market value of its parent company. Their results show that mispricing does not converge $30 \%$ of the time. In addition, they show that arbitrage profits are 50\% lower if the convergence path is relatively volatile rather than smooth. Moreover, the convergence path averages 236 days and ranges from 1 day to 2,796 days. These results indicate that mispricing can exist and persist for a significant period of time.

The limits of arbitrage and the persistence of mispricing can have adverse effects on financial as well as real economic variables. In an efficient capital market, in which prices reflect the underlying economic value of the security, prices work as a signal to investors to efficiently allocate their capital based on their risk preferences. Mispricing, on the other hand, may lead investors to misallocate their capital and end up with an inefficient allocation of capital. In addition, securities mispricing may also have real economic consequences. Several studies show that mispricing may affect managerial decisions such as equity issuance (Hertzel and Li, 2010), mergers and acquisitions (Rhodes and Viswanthan, 2004; and Rhodes-Kropf et al., 2005), and capital expenditure (Morck et al., 1990; and Chang et al., 2007). 
In this dissertation, I examine the effect of the limits of arbitrage on firm-specific mispricing of a sample of 8,170 firms $(59,591$ firm-year). In addition, I test the prediction of Shleifer and Summers (1990) and Shleifer and Vishny (1997) that specialization affects the ability of arbitrageurs to find close substitutes to mispriced securities. Moreover, I test another prediction of Shleifer and Vishny (1997) that addresses the effect of financial constraints on the ability of arbitrageurs to eliminate mispricing.

After that, I investigate whether there is a systematic difference in the limits of arbitrage between Standard \& Poor's 500 and non-S\&P 500 stocks. I expect S\&P 500 stocks to have, on average, lower levels of the limits of arbitrage, in the sense that it will lead to lower mispricing for these stocks, relative non-S\&P 500 stocks. I also examine if the lower mispricing can be attributed to their lower limits of arbitrage. I use various proxies for limits of arbitrage and a measure of mispricing based on a unique decomposition of the market-to-book ratio.

A large body of studies shows that as a stock is added to the S\&P 500 its liquidity and cost of capital improve; information asymmetries, volatility, transaction costs, and agency costs decline (e.g. Hedge and McDermott, 2003; Chen et. al, 2004; Vijh, 1994; Lin, 2007; Erwin and Miller, 1998; and others). Therefore, S\&P 500 stocks provide excellent conditions to examine the effect of the limits of arbitrage on the arbitrage process to eliminate stock mispricing.

The Standard \& Poor's 500 index is the most followed stock market index in the world. ${ }^{1}$ Its market capitalization is approximately US \$ 15.8 trillion dollars as of September 2013 and trillions of dollars are invested in index funds that mimic the index. In addition, the S\&P 500 is a natural benchmark against which investment managers evaluate their performance. Previous

\footnotetext{
${ }^{1}$ http://www.standardandpoors.com/about-sp/key-statistics-mhf/en/us
} 
studies examining index additions show that a positive (negative) abnormal return is associated with adding (deleting) a stock to (from) the S\&P 500. Early studies of this phenomenon suggests that the S\&P 500 inclusion criteria is public and contains no information. As a result, the S\&P 500 inclusion announcement represents a natural lab to examine asset pricing implications such as the slope of the demand curve for stocks.

This paper makes several contribution to the literature on securities mispricing. First, I decompose the M/B ratio into three components: firm specific mispricing, sector mispricing, and a long-term growth component based on Rhodes-Kropf et al. (2005). Then I examine the effect of the limits of arbitrage on firm specific mispricing for a large sample of publicly traded securities. Second, I develop a measure of the availability of substitutes for stocks, the proximity score, obtained from the fitted values of the propensity score matching technique, to empirically test the effect of the availability of substitutes on securities mispricing. Third, I empirically test the hypothesis that financial constraint has a positive impact on stock mispricing. After that, I examine the difference in the limits of arbitrage (e.g. volatility, transaction costs, and information uncertainty) and mispricing between S\&P 500 index members and non-S\&P 500.

The empirical results indicate that the availability of substitutes is an important determinant of stock mispricing. These findings are in line with the argument of Shleifer and Summers (1990), and Shleifer and Vishny (1997). In addition, the positive relationship between stock mispricing the absolute value of skewness supports the hypothesis that financial constraints that arise from the separation between arbitrageurs and capital may have an impact on stock mispricing. Also, the univariate tests show that the limits of arbitrage are significantly lower for the S\&P 500 stocks relative to other stocks. Furthermore, multivariate analysis suggests that S\&P 500 members have significantly lower mispricing relative to non-S\&500 members. 
In addition, the empirical results show arbitrage risk has a higher incremental effect on S\&P 500 stocks relative to non-S\&P 500 members. This result may indicate that the former group is efficiently priced to the extent that the marginal cost of eliminating an extra unit of mispricing is relatively high. Moreover, there is no significant evidence that information uncertainty has a lower impact on mispricing for S\&P 500 stocks relative to other stocks in the sample. This may arise because of the vast analyst and media coverage devoted to S\&P 500 stocks, which overcomes the information content in cash flow volatility. Additionally, I find no evidence that the low transaction costs of trading the S\&P 500 stocks have a lower effect on their mispricing.

This dissertation proceeds as follows: Section 2 presents the literature review on the limits of arbitrage and stock mispricing, S\&P inclusion criteria, and S\&P inclusion effect. Section 3 develops the hypotheses to be tested. Section 4 explains the methodology and data used in this paper. Section 5 shows the empirical results of this study. Finally, Section 6 concludes. 


\section{CHAPTER 2}

\section{BACKGROUND AND LITERATURE REVIEW}

This literature review is comprised of three parts. The first part discusses the limits of arbitrage, security mispricing, and market frictions and how they affect market efficiency. The second part gives a brief background on the criteria to add (remove) a stock to (from) the S\&P 500. The third part discusses the literature on what is known as the S\&P 500 inclusion effect. There is a general consensus that a positive (negative) abnormal return is associated with adding (deleting) a stock to (from) the S\&P 500. However, there are several hypotheses to explain this phenomenon. These hypotheses include: the price pressure hypothesis, the imperfect substitutes hypothesis, the certification (information) hypothesis, the liquidity hypotheses, and the investment awareness hypothesis.

\subsection{The Limits of Arbitrage and Stock Mispricing}

Arbitrage is defined as: "the simultaneous purchase and sale of the same, or essentially similar, security in two different markets for advantageously different prices" (Sharpe and Alexander, 1990). Textbook arbitrage as described in classical finance models, such as the efficient market hypothesis and CAPM, is an activity in which a large number of market participants exploit securities mispricing. The large number of traders implies that they take infinitesimal trades which in turn means that arbitrageurs do not face binding capital constraint. In addition, the small size of the trade also implies that traders are risk neutral to each trade. The combined effect of these small trades will result in efficient capital markets.

This description, however, does not capture many market characteristics. In reality, arbitrage takes place by fewer traders that are highly specialized in the market in which they are trading. Therefore, market frictions and conditions (e.g. idiosyncratic volatility, transaction costs, 
liquidity, and information asymmetries) are expected to reduce the ability of arbitrageurs to eliminate mispricing. Basak and Crotoru (2006) develop a model where heterogeneous beliefs and limited financing adversely affect the size of the arbitrage position due to decreasing marginal profit.

Information availability helps arbitrageurs to identify a mispriced security, which may be less clear when information is imprecise or uncertain. Zhang (2006) suggests that price continuation anomalies, namely price momentum and post-analyst forecast price drifts, are greater when in the presence of information uncertainty. In addition, Lin et al. (2010) examine the effect of hedging on stock mispricing and their results suggest that hedging reduces mispricing by improving the predictability of cash flows.

Tuckman and Vila (1992) analyze the effect of the holding costs (opportunity cost of capital) on mispricing and show that it can cause price to deviate from its fundamental value. In addition, they show that holding costs are significant in the treasury market. Pontiff $(1996,2006)$ classifies limits (costs) of arbitrage into two categories: holding costs, and transaction costs. An arbitrageur bears holding costs every period as long as the arbitrage position is held. Holding costs include idiosyncratic volatility and the opportunity cost of capital. Transaction costs, on the other hand, are incurred when the arbitrage position is initiated. Examples of these costs include brokerage fees and the bid-ask spread.

\subsubsection{Arbitrage Risk (Idiosyncratic Volatility)}

Black (1986) suggests that as noise (mispricing) increases in the price, informed traders will use their information to exploit mispricing, and volume is expected to increase. However, it is important to recognize that information provides an advantage but does not assure gains. In other words, using information to explore mispricing entails risk. 
Shleifer and Vishny (1997) suggest that arbitrageurs are highly specialized in the markets in which they trade. As a result, they are under-diversified and they are sensitive to idiosyncratic volatility arbitrageurs (Wurgler and Zhuravskaya, 2002; Ali et. al, 2003; and Mendenhall, 2004). Doukas et al. (2010) investigate the relationship between mispricing and arbitrage risk, measured by idiosyncratic volatility. Their results indicate that stocks with high unsystematic risk have higher estimated mispricing. These findings are not limited to small size stocks, high transaction costs stocks, and high book-to market stocks. In addition, Mashruwala et al. (2006) show that the accruals anomaly recognized by Sloan (1996), that is firms with a low (high) accruals component in their earnings earn positive (negative) abnormal return, is more prevalent in high idiosyncratic volatility stocks.

Previous literature demonstrates that some pricing anomalies are more pronounced in stocks with high idiosyncratic volatility. These anomalies include: closed-end funds discounts (Pontiff, 1996), index inclusion (Wurgler and Zharvskaya, 2002), momentum (Grundy and Martin, 2001), book-to-market anomaly (Ali et al., 2003), and post earnings announcement drift (Mendenhall, 2004).

Pontiff (2006) uses the mathematics of the Mean-Variance portfolio theory, Markowitz (1952), to present a stronger case for idiosyncratic volatility as a limit of arbitrage. In this model, a risk averse arbitrageur, with a risk aversion parameter equal to $\lambda$, is considering how to allocate his investment between a risk-free rate $\left(r_{f}\right)$, market portfolio $\left(r_{m}\right)$, and $n$ mispriced securities, such that the resulting portfolio has zero covariance with the market portfolio and all positions are uncorrelated. The return of the resulting portfolio $\left(r_{i}\right)$ is given by:

(1) $r_{i}=\alpha_{i}+r_{f}+e_{i}$ 
If the hedge position is mispriced, then $\alpha_{i}$ represents the alpha of the hedge portfolio. Since the portfolio has zero covariance with the market, then the volatility of the portfolio can be written as:

(2) $\sigma_{p}^{2}=\sigma_{m}^{2} x_{m}^{2}+\sum_{i=1}^{n} \sigma_{i}^{2} x_{i}^{2}$

where,

$x_{m}$ is the weight allocated to the market potfolio, $x_{i}$ is the weight allocated to security $i, \sigma_{m}^{2}$ is the variance of the market portfolio, and $\sigma_{i}^{2}$ is the variance of the hedge position.

The utility function of the investor is given by:

(3) $U=x_{f} r_{f}+x_{m} E\left(r_{m}\right)+\sum_{i=1}^{n}\left(\alpha_{i}+r_{f}\right) x_{i}-\frac{\lambda}{2} \sigma_{p}^{2}$

where,

$\lambda$ is the risk aversion parameter.

Solving for the optimal portfolio weights given that the sum of the weights is equal to one will produce the following results: ${ }^{2}$

(4) $x_{m}=\frac{\left(E\left(r_{m}\right)-r_{f}\right)}{\lambda \sigma_{m}^{2}}$

(5) $x_{i}=\left(\frac{\alpha_{i}}{\lambda \sigma_{i}^{2}}\right)$

Equation (5) suggests that the relevant factors in choosing the optimal weight in security $i$ are: the alpha of the position, the arbitrageurs risk aversion, and idiosyncratic volatility.

\footnotetext{
${ }^{2}$ The solution to the Pontiff (2006) optimization problem is provided in Appendix A
} 


\subsubsection{Transaction Costs}

Transaction costs in addition to idiosyncratic volatility, affect the ability of arbitrageurs to eliminate mispricing through their effect on liquidity. Arbitrageurs form their hedge portfolios and they expect to liquidate their positions in order to realize their profit at a future date and will bear transaction costs (Baker and Stein, 2004). These costs may arise to compensate market-makers for the adverse selection that results from information asymmetries when they trade with informed traders (Copland and Galai, 1983; Kyle, 1985; Easley and O'Hara, 2010; and Admati and Paul, 1988). Glosten and Milgrom (1985) suggest that trading costs are likely to be positive even if risk neutral market-makers face zero transaction costs. Another source of transaction cost is the inventory considerations of market makers that consider the bid-ask spread as price or compensation of the immediacy service that they provide (Demestez, 1968; Stoll, 1978; and Amihud and Mendelson, 1980).

As a result, investors will require a higher rate of return for stocks with higher transaction costs (Amihud and Mendelson, 1986). Therefore, arbitrageurs will have less incentive to arbitrage stocks with higher transaction costs. Sadka and Scherbina (2007), indicate that mispricing is higher for illiquid stocks. In addition, Mashruwala et al. (2006) show that the accruals anomaly is more severe for less liquid or high transaction costs stocks.

\subsection{S\&P 500 Eligibility Criteria}

\subsubsection{Additions}

In order to add a stock to the S\&P 500 index, the index committee follows a set of guidelines. ${ }^{3}$ These guidelines are:

\footnotetext{
${ }^{3}$ S\&P U.S Indices Methodology Manual, September 2013
} 
1. The home of domicile is the U.S based on SEC filings, fixed assets and revenues location, stock exchange, and corporate structure.

2. Market capitalization of $\$ 4.6$ billion or more. This lower bound subject to review from time to time based on market conditions.

3. Liquidity ratio greater than or equal to $1 .{ }^{4}$

4. A public float of $50 \%$ or greater

5. The company should represent the sector in which it operates in terms of market weight.

6. Four consecutive quarters of positive net income excluding discontinued operations and extraordinary items.

7. IPOs are not considered unless they are seasoned for 6 to 12 months

8. Eligible securities are common equities.

\subsubsection{Deletions}

S\&P 500 March 28, 2013 fact sheet states that: "The Index Committee strives to minimize unnecessary turnover in index membership and each removal is determined on case-by-case basis." However, the criteria to delete a stock from the index is as follows:

1. Companies that undergo significant restructuring, or are involved in mergers and acquisitions.

2. Companies that severely violate one or more of the additions criteria.

${ }^{4}$ Liquidity Ratio $=\left(\frac{\text { annual dollar value traded }}{\text { float adjusted } \text { market cap }}\right)$ 


\subsection{S\&P 500 Inclusion Effect}

\subsubsection{Price Pressure Hypothesis}

The price pressure hypothesis builds on modern finance theory and CAPM. The hypothesis suggests that since the demand curve for stocks is horizontal, any price change resulting from adding a stock to the S\&P 500 index is temporal and it will be reversed within a short period of time after the announcement. This price change is a short-term disruption or "short-term distribution effect" (Kraus and Stoll, 1972) that arises due to liquidity restrictions associated with large block trades. The price pressure effect can arise through several channels. First, due to the large flow, market makers may incur an inventory cost because of their deviation from optimum inventory levels. Second, matching large orders implies high search costs that will be absorbed by market makers, which in turn will widen the bid-ask spread. Keim and Madhavan (1998) provide empirical evidence that large block trades have a significant short-term price impact.

An early study by Harris and Gurel (1986) shows a positive average abnormal return of more than $3 \%$ on the announcement day. This abnormal return vanishes in two weeks after the announcement. Their work attracted many additional studies that look into the S\&P inclusion effect. Lynch and Mendenhall (1997) study the inclusion effect after Standard \& Poor's started to announce changes to the S\&P 500 index one week before the effective date. Their sample includes index additions (deletions) for the period 1990-1995. They breakdown the event window to announcement date $(\mathrm{AD})$ to change date $(\mathrm{CD})$. Their results show a positive (negative) abnormal return between the $\mathrm{AD}$ and the $\mathrm{CD}$. After the $\mathrm{CD}$, there is a partial reversal. These results show that abnormal returns have a temporal and permanent component (the latter will be discussed under the imperfect substitute hypothesis). 
Elliott and Warr (2003) investigated the difference between abnormal returns reversal patterns for stocks included in the NASDAQ (dealers market) relative to the NYSE and Amex (specialists markets). The empirical results show that there is an immediate reversal in the abnormal return of NYSE stocks included in the S\&P 500. On the other hand, the abnormal return associated with adding NASDAQ stocks shows a partial reversal that takes place in few days. These results suggest that a specialist system can handle the pressure resulting from order flows better than the dealer system.

\subsubsection{Imperfect Substitutes Hypothesis}

The imperfect substitutes hypothesis suggests that stocks are imperfect substitutes and hence their demand curve is negatively sloped. As a result, as a stock is added to the S\&P 500 the price change associated with event is permanent and represents a new equilibrium level. The large flow of orders will influence prices when investors require higher prices in order to change their current portfolios.

The pioneering work of Shleifer (1986) shows that adding a stock to the S\&P 500 results in $3 \%$ positive abnormal return on announcement date and it persists for 20 days after announcement. The abnormal return is greater than what can be attributed to transaction costs. Therefore, he concludes that price change is a result of the increasing demand of index fund which in turn causes a shift to the negatively sloped demand curve. Consistent with this result, Pruitt and Wei (1989) show that institutional ownership increases (decreases) with S\&P 500 additions

(deletions). Beneish and Whaley (1996) and Lynch and Mendenhall (1997) analyze the effect of the new announcement policy where Standard and Poor's preannounces changes few days to one week before the change actually takes place. The abnormal return for added stock under the new announcement policy is still positive on the change date but lower than the previous policy. 
In a related study, Kaul et. al (2000) examined the abnormal returns associated with an "information free" event; that is the Toronto Stock Exchange (TSE) 1996 weight revision. Since the event is information free, then any positive abnormal return is attributed to stocks negatively sloped demand curve. They find positive abnormal returns that outlive the increase of the volume and they also find a partial reversal. These findings support the imperfect substitute hypothesis and hence a downward sloping demand curve. In other international markets, Chakrabarti et al. (2005) investigate the inclusion effect in international markets, specifically the MSCI. The results show a positive cumulative abnormal return of 5\% following 10 days of announcement. On the other hand, deleted stocks show a negative cumulative abnormal return of $-7.5 \%$. The volume shows an increase of 3\%. These results, in general, support the imperfect substitute hypothesis and liquidity hypothesis.

In an influential study, Wurgler and Zhuravskaya (2002) study the price behavior of stocks with close substitutes (low idiosyncratic risk) and stocks with no close substitutes (high idiosyncratic risk) when they are added to the S\&P 500 index. The results show that the price increase is higher for stocks with no close substitutes. In other words, demand curve is flatter for stocks that have close substitutes. Morck and Yang (2001) suggested that if the increase in value is permanent, then this increase will also be reflected in S\&P 500 members Tobin's q. ${ }^{5}$ Empirical results suggest that Tobin's $\mathrm{q}$ is higher for index members compared to a size based matching sample.

\footnotetext{
5 Tobin's q=the market value of the financial claims on a firm to the replacement cost of assets. Tobin (1978) suggests that the q ratio captures investment opportunities. Lindenberg and Ross (1981) claim that the q ratio measures monopoly rents.
} 


\subsubsection{Certification (Information) Hypothesis}

A key assumption in the previous hypotheses is that index addition (removal) is an information free event. This assumption is partially supported by the following statement from the S\&P 500 index methodology manual:”...the decision to include a company in the S\&P 500 Index is not an opinion on that company's investment potential." However, the inclusion criteria includes financial viability and more importantly Standard and Poor's explicitly states in the fact sheet that "The Index Committee strives to minimize unnecessary turnover in index membership and each removal is determined on a case-by-case basis." The inclusion criteria and the statement imply that the Index Committee, which includes economists and index analysts, uses its financial expertise to add stocks to the index and they expect the stock to maintain the addition criteria for a long period of time.

Several studies investigated the information content of index additions and deletions. For example, Goetzmann and Garry (1986) examine excess return for six delisted companies from the S\&P 500. They found a negative abnormal return for the delisted companies and they attribute the price drop to the "... anticipation of future decrease in available information." Jain (1987) studied the inclusion effect on the supplementary index published by Standard and Poor's. The supplementary index consists of 40 companies that are not included in the S\&P 500 index. The author contacted several index funds and they acknowledged that they do not include supplementary index constituents in their portfolios. The results show positive abnormal return for the supplementary index and a t-test does not show a significant difference between the control group and the added stocks. These findings indicate that the S\&P inclusion effect may arise from the "positive information" content in the announcement. 
In a later study, Cai (2007) tests the certification hypothesis by creating a matching sample, by size and industry, and examines abnormal return around the inclusion of a matching firm. The results show that there exists a slightly positive abnormal return in the matching sample which is negatively related to the industry's weight of the included firm. The positive excess return suggests that including a stock in the S\&P 500 contains positive information about the industry. The difference in abnormal return magnitude between the included firms and the matching sample arises because the latter does not contain the firm specific information favored by the Index Committee. On the other hand, there is no similar effect that appears in volume. These results suggest that the inclusion announcement conveys positive information about the included firm and its industry.

Dhillon and Johnson (1991) analyze the inclusion effect not only on newly added stocks, but also on their derivatives (calls, and puts), and bonds. If the price pressure hypothesis is correct, then option prices should remain unchanged because the future distribution of stock returns is unaffected. However, if both call and stock prices increase, then we expect stocks with traded options to have lower excess return compared to stocks without traded options. Market makers in the stock market will share price pressure with their counterpart in the options market. This in turn will result in a lower price change for stocks with traded options. The empirical results show that call prices indeed increase and put prices, however, decrease; this is inconsistent with the price pressure hypothesis. The analysis of bonds markets shows that they react positively. The reaction of other asset classes associated with the company suggest that adding a stock to the index contains positive information about the firm.

Denis et al. (2003), compare analysts' forecasts and earnings pre and post inclusion to the S\&P 500 relative to a matching sample. The empirical results show that EPS forecasts and realized 
earnings witness a significant increase after a stock is added to the S\&P 500. These results indicate that index inclusion is not an information free event.

\subsubsection{Liquidity Hypothesis}

As a stock is added to the S\&P 500, the increased institutional ownership (Pruitt and Wei, 1989), may increase the liquidity of the stock which will appear in the form of lower bid-ask spread. In addition, increased monitoring may lower information asymmetries which in turn are expected to reduce bid-ask spread. Amihud and Mendelson (1986) show that securities with higher liquidity will have a lower required rate of return and hence a higher value. Therefore, the liquidity hypothesis suggests that the positive price reaction to the added stocks is simply a result of the expected liquidity improvement.

Erwin and Miller (1998) examine the inclusion effect on liquidity as measured by bid/ask spread and volume. They split the sample into two categories: optioned stocks and non-optioned stocks. Their results show that there is a significant decrease in the bid/ask spread for the nonoptioned stocks and a significant increase in trading volume. On the other hand, optioned stocks show a permanent positive effect on volume only. These results are attributed to the arbitrage that takes place between a stock and its options, which increases informational efficiency (Danthine, 1978; Grossman, 1988). Hedge and McDermott (2003) investigate the liquidity effect on stocks added to (deleted from) the S\&P 500. The empirical results show that a stock's addition to (deletion from) the index is associated with an increase (a decrease) in trading frequency, and a decrease (increase) in the spread for three months after the event takes place. These results suggest that S\&P 500 index membership is associated with better liquidity, and lower transaction costs. 


\subsubsection{Investment Recognition (Awareness) Hypothesis}

With regard to the investor Recognition Hypothesis (IRH), Merton (1987) proposes that in the presence of incomplete information on securities characteristics, some investors will hold under-diversified (sub-optimal) portfolios relative to the CAPM world. In order to hold suboptimal portfolios, investors will require compensation for idiosyncratic risk. Therefore, adding a stock to the S\&P 500 increases investors' recognition and will reduce the idiosyncratic risk premium. As a result, the required rate of return is expected to decline and hence stock price is expected to increase.

Another related model is the style investing model. In this model, Investors have the tendency to group assets into classes or "styles". This tendency arises because it simplifies the choice cost by reducing the amount of information to be processed. In addition, the emergence of asset classes (small cap, large cap, value investing, growth investing,...etc.) naturally creates benchmarks against which investors evaluate their relative performance. Barberis and Shleifer (2003) build a model to analyze the effect of style investing on the behavior of asset prices. The two key assumptions in their model are: 1) investors allocate their investments to styles based on relative past performance, 2) funds movement between styles affects prices. The model predicts that when an asset is added into a class, the correlation of the asset increases with the group even if the cash flow correlations did not change. As a class of assets starts to show positive fundamentals, it attracts investors and the funds flow increase prices.

Chen et al. (2004), analyze the effect of stocks' addition to and deletion from the S\&P 500. The added stocks show a permanent positive abnormal return. However, deleted stocks show a temporary decrease that persists for three months. This asymmetric response is consistent with the investment awareness hypothesis proposed by Merton (1987). The model suggests that investors 
are only aware of a subsample of the market. Therefore, they are under-diversified and hence they require compensation for idiosyncratic risk. Adding a stock to the S\&P 500 increases investors awareness for that stock. As a result, they require a lower rate of return on the stock; which is manifested by a positive abnormal return. However, when a stock is deleted, the information revealed upon addition does not easily disappear. This idea is reflected in the temporary decline of the stock price. Other explanations of the S\&P 500 inclusion effect (price pressure, imperfect substitutes, certification, and liquidity) imply a symmetric price effect for additions and deletions. 


\section{CHAPTER 3}

\section{HYPOTHESES DEVELOPMENT}

The investigation of the relationship between the limits of arbitrage and stock mispricing is carried out in two stages. In the first stage I decompose the $\mathrm{M} / \mathrm{B}$ ratio into three components: firm specific mispricing, sector mispricing, and long-term growth components. After that, I use the first component as a dependent variable to examine the effect different proxies of the limits of arbitrage on stock mispricing. Specifically, I test the effect of the availability of substitutes and arbitrageurs financial constraints on the magnitude of mispricing.

In the second stage, I examine if there is a systematic difference in the proxies of the limits of arbitrage between S\&P 500 members and non-S\&P 500 members. Then, I examine if S\&P 500 stocks have lower mispricing relative to non-S\&P 500. After that, I conduct an empirical investigation to see if the lower mispricing of the index-members can be attributed to the lower limits of arbitrage.

\subsection{Availability of Substitutes and Financial Constraints Hypotheses}

Efficient markets and the CAPM paradigm suggests that arbitrageurs can create arbitrage portfolios by selecting securities, or create portfolios that have the same risk characteristics as the mispriced security and eliminate mispricing. However, Shleifer and Vishny (1997) argue that arbitrageurs are highly specialized and financially constrained. Specialization restricts arbitrageurs by limiting the universe from which they can create their arbitrage portfolio. In addition, Shleifer and Summers (1990) indicate that arbitrage that includes securities that have close substitutes is risky and mispricing is expected to persist. As a result, in the Shleifer and Vishny (1997) and the Shleifer and Summers (1990) world, it is harder for specialized arbitrageurs to find a substitute for 
a mispriced stock and eliminate mispricing. Therefore, I expect stocks that have no close substitutes to have higher mispricing. This hypothesis can be formally stated as:

\section{$H_{1} \quad$ The greater the difference between a stock and its closest substitute, $C P$, the higher the mispricing.}

In addition, financially constrained arbitrageurs do not have infinite access to capital and face the need to raise external capital. This separation between capital and arbitrageurs creates an agency problem. While arbitrageurs construct their portfolios based on their expertise, capital providers cannot observe the expected value of the arbitrage portfolio. What they observe instead is the past performance and the current value of the arbitrage portfolio (Shliefer and Vishny, 1997; and Liu and Longstaff, 2004). As a result, if any negative shock affects the value of the arbitrageurs' holdings, then capital providers may force arbitrageurs to prematurely liquidate their portfolios before they realize their expected profit (Stein, 2009). Therefore, mispricing is expected to be higher when arbitrageurs are financially constrained. This hypothesis can be formally stated as:

$\mathrm{H}_{2} \quad$ Arbitrageurs financial constraints will have a positive impact on stock mispricing.

\subsection{Index Membership and Stock Mispricing Hypotheses}

Previous studies show that the inclusion announcement is associated with a positive abnormal return. This abnormal return might be driven by changes in liquidity (Erwin and Miller, 1998), volatility (Lin, 2007), changes information asymmetries and information uncertainty (Denis et. al, 2003), or transaction costs (Hedge and McDermott, 2003). Therefore, I expect S\&P 500 stocks to have, on average, lower limits of arbitrage relative to non-S\&P 500. This hypothesis can be formally stated as: 
$H_{3} \quad S \& P 500$ members have, on average, lower limits of arbitrage relative to non-S\&P 500 stocks, $C P$.

Since limits of arbitrage are expected to be lower for S\&P 500 members relative to nonS\&P 500 stocks, then arbitrageurs are expected to be able to reduce mispricing and bring prices closer to fair value. Therefore, I expect S\&P 500 members have lower mispricing relative to nonS\&P 500 stocks.

$\mathrm{H}_{4} \mathrm{~S} \& \mathrm{P} 500$ stocks have, $\mathrm{CP}$, lower mispricing compared to non-S\&P 500 stocks.

After testing these four hypotheses, I investigate the empirical relationship between the limits of arbitrage and mispricing for S\&P 500 members and non-S\&P 500 stocks. Arbitrage risk is an important determinant of the ability of arbitrageurs to eliminate mispricing (Shleifer and Vishny, 1997). Generally, arbitrage risk is expected to have a positive effect on securities mispricing (Pontiff, 2006; and Doukas et al., 2010). However, the incremental effect of arbitrage risk on S\&P 500 stocks mispricing may be different than non-S\&P 500 stocks. Since S\&P 500 stocks are expected to have lower mispricing relative to non-S\&P 500 members, it may be less risky to arbitrage S\&P 500 stocks because of the high probability of price to converge to its fair value. However, the effect of arbitrage risk may be higher for S\&P 500 stocks because of the increasing marginal cost of arbitrage. In other words, S\&P 500 members are efficiently priced in a way similar to the pricing described in Grossman and Stiglitz (1980) in which the marginal benefit of the position is equal to the marginal holding cost. As a result, the marginal cost of eliminating an extra unit of mispricing might be higher.

In order for the arbitrage process to take place, arbitrageurs need information to identify mispriced securities. As a result, arbitrage is expected to be more prevalent in securities with more 
precise information. The S\&P inclusion effect may be driven by the information content of the announcement and/or the information production that results from increased analysts' coverage (Goetzmann and Garry, 1986; and Dhillon, and Johnson, 1991, and Denis et. al 2003). Therefore, information uncertainty may have a negative incremental effect on S\&P 500 stocks mispricing relative to non $\mathrm{S} \& \mathrm{P}$ stocks.

Previous studies suggest that as a stock is added to the S\&P 500, its liquidity increases and its transaction costs decrease (Hedge and McDermott, 2003). Therefore, transaction costs are expected to be lower for S\&P 500 stocks and may have a lower effect on firm specific mispricing for S\&P 500 stocks. 


\section{CHAPTER 4}

\section{METHODOLOGY}

\subsection{Mispricing Measure}

In this paper I follow the methodology proposed by Rhodes-Kropf et al. (2005) to measure stock mispricing ${ }^{6}$. In order to estimate mispricing, the $\mathrm{M} / \mathrm{B}$ ratio is decomposed into two components: the market price to true value ratio $(\mathrm{M} / \mathrm{V})$, and the true value to book ratio (V/B):

(6) $M /{ }_{B}=M / V \times V / B$

Transforming equation (1) to the natural log form we get:

(7) $m-b \equiv(m-v)+(v-b)$

where, lower case letters denote the natural logarithmic values of the stated variables. In a frictionless capital market, market price is equal to the true value. Therefore, the difference between $m$ and $v$ is always zero, and hence the market to book ratio will capture growth opportunities. In less than perfect capital markets, where limits of arbitrage and/or irrational pricing exist, the difference between market value and true value will represent the mispricing component of the $\mathrm{M} / \mathrm{B}$ ratio.

Moreover, Rhodes-Kropf et al. (2005) argue that the difference between market price and true value can be attributed to price deviation of firm $i$ from the value implied by the firm-specific time $t$ fundamentals (firm specific mispricing) and/or time $t$ fundamentals itself may deviate from long-term sector $j$ fundamentals (sector mispricing). Therefore, equation (2) can be extended to the following three components:

\footnotetext{
${ }^{6}$ This discussion closely follows Rhoded-Khropf et al. (2005)
} 
(8) $m_{i t}-b_{i t} \equiv\left[m_{i t}-v\left(\theta_{i t} ; \alpha_{j t}\right)\right]+\left[v\left(\theta_{i t} ; \alpha_{j t}\right)-v\left(\theta_{i t} ; \alpha_{j}\right)\right]+\left[v\left(\theta_{i t} ; \alpha_{j}\right)-b_{i t}\right]$

where, $v$ represents value based on accounting information at time $t, \theta_{i t}$, and aggregate multiples, $\alpha$. Note that time $t$ multiples are subscripted $j t$, whereas long-term multiples are subscripted $j$. Therefore, the first term in equation (3), $m_{i t}-v\left(\theta_{i t} ; \alpha_{j t}\right)$, captures the difference between firm $i$ market price and value implied by sector fundamentals at time $t$. This term represents firm-specific-mispricing. The second term, $v\left(\theta_{i t} ; \alpha_{j t}\right)-v\left(\theta_{i t} ; \alpha_{j}\right)$, reflects sector $j$ 's value at time $t$ relative to long-term sector multiples, sector-mispricing. The last term, $v\left(\theta_{i t} ; \alpha_{j}\right)-$ $b_{i t}$, is the difference between long-term sector multiples and book value. This term is inferred as the growth-component implied by investment opportunities.

In order to estimate the unobservable intrinsic value, Rhodes-Kropf et al. (2005) build on Ohlson's (1995) residual income model. This model identifies the intrinsic value as the sum of the value of the asset in place and the sum of the expected discounted residual income. Equation (4) shows the model in discrete time: ${ }^{7}$

(9) $M_{t}=B_{t}+E_{t}\left[\sum_{\tau=t+1}^{\infty} \frac{\left(R O E_{\tau}-r_{\tau}\right) B_{\tau-1}}{\left(1+r_{\tau}\right)}\right]$

where, $M_{t}$ is the intrinsic value of equity at time $t, B_{t}$ is the book value of assets at time $t, R O E_{\tau}$ is return on equity, and $r_{\tau}$ represents the discount rate. Frankel and Lee (1998) show that the residual income model produces robust and better cross-sectional stock returns prediction compared to simple market multiples, namely the $\mathrm{B} / \mathrm{M}$ ratio.

\footnotetext{
${ }^{7}$ The model in continuous time is given by: $M_{t}=B_{t}+\int_{t}^{\infty} e^{\int_{t}^{\tau} r(\eta) d \eta} R I d_{\tau}$ where, $r(\eta)$ is the time varying discount rate, and RI is the residual income or the economic value that arises from an asset in excess of its opportunity cost.
} 
To empirically estimate the three components, Rhodes-Kropf et al. (2005) assume that value can be written as a linear function of book value, net income and leverage, ${ }^{8}$

(10) $M_{t}=\alpha_{0}+\alpha_{1} B_{t}+\alpha_{2} N I_{t}+\alpha_{3} L E V_{t}$

After that, I estimate equation (5) using the following regression model:

(11) $m_{t}=\alpha_{0 j t}+\alpha_{1 j t} b_{i t}+\alpha_{2 j t} n i_{i t}^{+}+\alpha_{3 j t} I_{(N I<0)} n i_{i t}^{+}+\alpha_{4 j t} L E V_{i t}+\varepsilon_{i t}$

where, $b_{i t}$ is the natural log of book value of equity (item \# 60) $n i_{i t}^{+}$is the natural log of the absolute value of net income (item \# 172), $I_{(N I<0)}$ is an indicator variable that is equal to one if the income is negative and zero otherwise, and $L E V_{i t}$ is the leverage ratio. ${ }^{9}$

(12) $L E V=\left(1-\frac{\text { Market Value of Equity }}{\text { Market Value of Assets }}\right)$

Since the regression model in equation (6) contains log of net income, we use the indicator variable to include firms with negative income values without dropping observations out of the sample.

To estimate equation (6), I classify firms into the 12 Fama and French industries and estimate an annual cross-section regression for each industry-year. ${ }^{10}$ Estimating a separate equation for each year allows growth rates and/or discount rates to change over time. After that, I use the parameter estimates from equation (6) for each industry year to calculate the intrinsic value of the stock based on its accounting multiples, $v\left(\theta_{i t} ; \alpha_{j t}\right)$, at time $t$ :

(13) $v\left(B_{i t}, N I_{i t}, L E V_{i t} ; \hat{\alpha}_{0 t}, \hat{\alpha}_{1 t}, \hat{\alpha}_{2 t}, \hat{\alpha}_{3 t}, \hat{\alpha}_{4 t}\right)=$

\footnotetext{
${ }^{8}$ Rhodes-Kropf et al. (2005) suggest three models of value. Value as a function of: (1) book value, (2) book value and net income; and (3) book value, net income, and leverage. The presented model is model 3

${ }^{9}$ Market Value of Equity (MVE)=price (item \#199) xcommon shares outstanding (item \#25)

Market Value of Assets=MVE+total assets (item \#6)-deferred taxes (item \# 74)-book value of equity (item \# 60)

${ }^{10}$ Fama and French 12 industries definitions are obtained from French's website:

http://mba.tuck.dartmouth.edu/pages/faculty/ken.french/Data_Library/det_12_ind_port.html
} 


$$
\hat{\alpha}_{0 j t}+\hat{\alpha}_{1} b_{i j t}+\hat{\alpha}_{2 j t} n i_{i t}^{+}+\hat{\alpha}_{3 j t} I_{(N I<0)} n i_{i t}^{+}+\hat{\alpha}_{4 j t} L E V_{i t}
$$

for all firms in the sample each year. To obtain the long term value, $v\left(\theta_{i t} ; \alpha_{j}\right)$, we take the timeseries average of the coefficients estimated in equation (6):

(14) $\overline{\alpha_{j}}=\frac{1}{T} \sum_{t=1}^{T} \alpha_{t}$

Then, we use the average coefficients to obtain the long-run value of the stock:

$$
\begin{aligned}
& v\left(B_{i t}, N I_{i t}, L E V_{i t} ; \bar{\alpha}_{0 t}, \bar{\alpha}_{1 t}, \bar{\alpha}_{2 t}, \bar{\alpha}_{3 t}, \bar{\alpha}_{4 t}\right)= \\
& \bar{\alpha}_{0 t}+\bar{\alpha}_{1} b_{i t}+\bar{\alpha}_{2} n i_{i t}^{+}+\bar{\alpha}_{3} I_{(N I<0)} n i_{i t}^{+}+\bar{\alpha}_{4} L E V_{i t}
\end{aligned}
$$

Therefore, we obtain the mispricing measure in equation (3):

(16) $M i s_{i t}=m_{i t}-v\left(B_{i t}, N I_{i t}, L E V_{i t} ; \hat{\alpha}_{0 t}, \hat{\alpha}_{1 t}, \hat{\alpha}_{2 t}, \hat{\alpha}_{3 t}, \hat{\alpha}_{4 t}\right)$

Alzahrani and Rao (2014) decompose the market-to-book ratio and use the mispricing component and long-term growth component to analyze the effect of stock mispricing on corporate investment decisions. In addition, Hertzel and $\mathrm{Li}$ (2010) use the mispricing component to investigate the effect of stock mispricing on the firms' decision to issue equity.

The mispricing measure, $M i s_{i t}$, represents the error term obtained from estimating an annual cross-sectional regression estimated for each of the 12 Fama and French industries. The firm specific mispricing can be interpreted as the deviation of the firm price from the value implied by the contemporaneous industry information captured in the accounting multiples.

For the purpose of this study, I use the absolute value of mispricing, $\left|M i s_{i t}\right|$, because we are interested in the magnitude of mispricing rather than the direction of mispricing: 


$$
\left|M i s_{i t}\right|=\left|m_{i t}-v\left(B_{i t}, N I_{i t}, L E V_{i t} ; \hat{\alpha}_{0 t}, \hat{\alpha}_{1 t}, \hat{\alpha}_{2 t}, \hat{\alpha}_{3 t}, \hat{\alpha}_{4 t}\right)\right|
$$

Ponitff (1996) uses the absolute value of the closed-end fund discount to investigate the effects of the limits of arbitrage on the closed-end fund discount puzzle. Figure 1 shows the average annual mispricing for the sample in hand for the period 1982-2012. The average mispricing of the market was at its highest before what is known as the dot com (.com) bubble which burst at the beginning of the second millennia. Another episode of the sharp increase in mispricing can be seen before the recent financial crises of 2007.

\section{[Insert Figure 1 here]}

\subsection{Availability of Substitutes and Financial Constraints Measures}

\subsubsection{Availability of Substitutes Measure (Proximity Score)}

In order to measure availability of substitutes, I develop a proximity score that measures the distance between a stock and its closest substitute. The proximity score is calculated based on propensity scores obtained from the propensity score matching technique. Propensity score matching is an econometric matching technique that enables us to create a matching sample based on several characteristics, rather than one dimensional matching such industry-size matching (e.g. Ritter, 1991). ${ }^{11}$ Propensity scores are estimates of the likelihood that an observation or a member of a group is likely to behave similar to a control group based on several control characteristics. Bartram et al. (2011) use the propensity score matching technique to create a matching sample for companies that use derivatives to analyze the effect of using derivatives on firm risk and value. In addition, Bartram et al. (2012) investigate why U.S. stocks are more volatile relative to foreign

\footnotetext{
${ }^{11}$ Propensity score matching is established by Rosenbaum and Rubin (1983) and further developed by Heckman et al. $(1997,1998)$
} 
firms and they use propensity score matching to match foreign firm with similar characteristics to U.S. firms.

Propensity scores are obtained in two steps. First, a logit (probit) regression is estimated with a dependent variable equal to one (an S\&P 500 member in this case) if the firm has the required characteristic and 0 if not. The control variables represent the matching characteristics that are expected to influence the control group members. In the arbitrage context, the relevant control variables are the risk factors that are used to mimic the payoff of a mispriced security. A natural choice is the Fama and French three-factors: stock beta, size, and book-to-market ratio (Fama and French, 1992). ${ }^{12}$ In the second step, the predicted values obtained from the estimated model are used to match observations with the most similar propensity scores.

I use the following model with an underlying logit probability density function to estimate propensity scores:

(17) $P_{i t}^{*}=\gamma_{0}+\gamma_{1} \beta_{i t}+\gamma_{2} \operatorname{Size}_{i t}+\gamma_{3} B M_{i t}+\varepsilon_{i t}$

where, $P_{i t}^{*}$ is a continuous measure of propensity that can be observed through a binary variable that equals 1 if the stock is a member of the $\mathrm{S} \& \mathrm{P} 500$, and 0 otherwise, $\beta_{i t}$ is the beta of stock $i$ at time $t$, Size $_{i t}$ is the $\log$ of market value of the equity of stock $i$ at time $t$; and $B M_{i t}$ is the book-tomarket ratio of stock $i$ at time $t$. This model is estimated for each industry-year in the sample. ${ }^{13}$

\footnotetext{
${ }^{12}$ The Fama and French three-factor model is given by: $R_{i t}=\alpha+\beta_{i m} M R P_{t}+\beta_{i h} H M L_{t}+\beta_{i s} S M B_{t}+\varepsilon_{i t}$ where, $R_{i t}$ is the return of stock $i$ in excess of the risk free rate, $M R P_{t}$ is the market risk premium at time $t, H M L_{t}$ is the return of high book-to-market portfolio minus the low book-to-market portfolio, and $S M B_{t}$ is he return on the small size portfolio minus the return on the large size portfolio.

${ }^{13} \beta_{i t}$ is calculated by regressing the weekly stock $i$ return at time $t$ on CRSP value weighted market portfolio, the market model:

$R_{i t}=\alpha+\beta R_{m t}+\varepsilon_{i t}$
} 
After that, I obtain the predicted value of the propensity score for each stock in the sample and calculate the difference between the fitted value of each stock and its closest match. If the difference is zero, then the stock has a perfect match. On the other hand, if the difference is not, then the stock does not have a perfect substitute. As a result, I expect the higher the difference, the highest the magnitude of mispricing. In the context of this study, I use the proximity score as a proxy for the availability of substitutes.

\subsubsection{Financial Constraints Measure}

In order to investigate the effect of financial constraints on security mispricing, I use the absolute value of return skewness as a proxy for financial constraints. Yuan (2005) suggests that “... asset returns exhibit more skewness in markets where investments are highly specialized and agency problems are more acute." The following is the logic behind using skewness as a measure of financial constraints. Shleifer and Vishny (1997), as discussed earlier, argue that the separation between arbitrageurs and capital creates an agency problem. Since arbitrageurs are specialized and base their decisions on their expertise in the markets in which they operate, capital providers do not have the ability to see the expected value of the arbitrage portfolio. Therefore, if the value of the portfolio declines, the arbitrageurs face the risk that capital providers may force them to liquidate their position before it matures. Adrian and Rosenberg (2008) decompose market volatility into short term and long term volatility and they relate skewness to the latter component.

The possibility that arbitrageurs may early liquidate their position is expected to make them more sensitive to negative outcomes. For example, if an arbitrageur is holding a long position on an underpriced security, he is expected to be more vulnerable to price declines or below average

outcomes. Therefore, in this case the arbitrageur prefers a negatively skewed distribution of 
returns. On the other hand, if the arbitrageur is holding a short position of an overpriced security then he is more sensitive to price increases or above average outcomes. As a result, arbitrageurs are expected to prefer securities with a more symmetric distribution of returns to reduce the probability of unfavorable outcome (positive skewness in the case of long positions and negative skewness in the case of short positions). Thus, as the absolute value of skewness increases, I expect mispricing to increase.

\subsection{Empirical Model and Independent Variables}

In order to empirically investigate the effect of the limits of arbitrage and the availability of substitutes and financial constraints on securities mispricing, I use the following regression model:

$$
\begin{aligned}
& \mid \text { Mis }_{i t} \mid=\alpha_{i}+\beta_{1} A R_{i t}+\beta_{2} \text { SIZE }_{i t}+\beta_{3} \text { CFVOL_AT } i t \\
&+\beta_{4} O w n_{-} \text {Conc }_{i t} \\
&+\beta_{5} \text { BIDASK }_{i t}+\beta_{6} \text { DPO }_{i t}+\beta_{7} \text { Prox }_{i t}+\beta_{8} \mid \text { Skew }_{i t} \mid+\varepsilon_{i t}
\end{aligned}
$$

where,

$\left|M i s_{i t}\right| \quad$ Absolute value of firm specific mispricing (equation 11). Pontiff (1996) indicates that using the absolute value of mispricing (closed-end funds discount in his paper), instead of the level of mispricing is the appropriate measure because the limits of arbitrage are related to the magnitude of mispricing not to the direction of mispricing.

$A R_{i t} \quad$ Arbitrage risk, which is measured as the standard deviation of the error term resulting from regressing weekly stock return on the Fama and French three factors model. Idiosyncratic volatility is a proxy for arbitrage cost (Pontiff, 1996; Wurgler and Zhuravskaya, 2002; and McLean, 2010). 
$S I Z E_{i t} \quad$ The natural $\log$ of market value of equity. Market value of equity is calculated as the number of shares outstanding times the price at the fiscal year end (item\# $25 \times$ item \# 199); Wurgler and Zhuravskaya (2002); and Ali et al. (2003).

CFVOL_AT $T_{i t}$ Cash flow volatility, measured as the standard deviation of cash flow from operations over the previous five years scaled by total assets. Cash flow from operations (CFO) is calculated as: income before extraordinary items (item\# 18) minus total accruals, scaled by total assets (item\# 6). Accruals are calculated as the change in current assets (item\# 4), minus the change in cash (item\# 1), the change in depreciation (item\# 14), and the change in current liabilities (item\# 5) plus the change in short-term debt (item\# 34) This measure is a proxy for information uncertainty (Zhang, 2006; and Lam and Wei, 2011).

Own_Conc ${ }_{i t}$ Ownership concentration, measured by dividing the number of shares outstanding by the number of shareholders (item\# 25/ item\# 100); Armstrong et al. (2011). This variable measures the institutional ownership.

BIDASK $_{i t}$ Bid-Ask spread, which is measured as the time series average over the year of the weekly absolute value of the difference between the bid and ask divided by price. BIDASK $_{\text {it }}$ is a measure of transaction costs (Lam and Wei, 2011).

$D P O_{i t} \quad$ Dividends payout ratio, measured by dividing dividends to common shareholders (item\# 21), dividends to preferred shareholders (item\# 19), and stock repurchases (item\# 115) divided by operating income before depreciation (item\# 13), (Lam and Wei, 2011). Pontiff (1996) suggests that stocks with high dividends payout ratios are easier to hedge and hence they are expected to have lower mispricing. 
$\operatorname{Prox}_{i t} \quad$ Proximity score, calculated as the difference between the predicted value of the propensity score and its closest match in each industry-year.

$\left|S_{k e w}\right| \quad$ Skewness of weekly returns of stock $i$ at time $t$. This variable measures financial constraint (Yuan, 2005; and Adrian and Rosenberg, 2008)

The availability of substitutes hypothesis $\left(\mathrm{H}_{1}\right)$ states that stocks that have no close substitutes are expected to have higher mispricing. Therefore, I expect the parameter on the variable $\operatorname{Prox}_{\mathrm{it}}\left(\beta_{7}\right)$ the previous equation to be positive and statistically significant. Moreover, the financial constraints hypothesis $\left(\mathrm{H}_{2}\right)$ predicts that financial constraints limit the ability of arbitrageurs to eliminate mispricing. Financial constraints are more binding for stocks with more skewness because of the asymmetrical distribution that may increase the probability of unfavorable outcomes. Hence, I expect the parameter on the variable $\mid$ Skew $\mathrm{w}_{\mathrm{it}} \mid\left(\beta_{8}\right)$ in equation (18) to be positive and statistically significant.

In the second stage, I use the following regression model to show that S\&P 500 firms have, on average, lower mispricing relative to non-S\&P 500 stocks:

$$
\begin{aligned}
& \text { (19) }\left|M i s_{i t}\right|=\alpha_{i}+\beta_{1} A R_{i t}+\beta_{2} S_{I Z E_{i t}}+\beta_{3} \text { CFVOL_AT } i t+\beta_{4} O w n_{-} \text {Conc }_{i t} \\
& +\beta_{5} \text { BIDASK }_{i t}+\beta_{6} D P O_{i t}+\beta_{7} \operatorname{Prox}_{i t}+\beta_{8} \mid \text { Skew }_{i t} \mid \\
& +\delta_{1} S \& P_{i t}+\delta_{2}\left(S \& P_{i t} \times A R_{i t}\right)+\delta_{3}\left(S \& P_{i t} \times S I Z E_{i t}\right) \\
& +\delta_{4}\left(S \& P_{i t} \times C F V O L_{-} A T_{i t}\right)+\delta_{5}\left(S \& P_{i t} \times O w n_{-} C_{o n}\right) \\
& +\delta_{6}\left(S \& P_{i t} \times B I D A S K_{i t}\right)+\delta_{7}\left(S \& P_{i t} \times D P O_{i t}\right) \\
& +\delta_{8}\left(S \& P_{i t} \times \operatorname{Prox}_{i t}\right)+\delta_{9}\left(S \& P_{i t} \times\left|S k e w_{i t}\right|\right)+\varepsilon_{i t}
\end{aligned}
$$


where,

$S \& P_{i t} \quad$ An indicator variable set equal to 1 if the company is an S\&P 500 index member and 0 if not.

$S \& P_{i t} \times X_{i t} \quad$ An interaction dummy variable that multiplies each independent variable by the indicator variable $S \& P_{i t}$

The third hypothesis $\left(\mathrm{H}_{3}\right)$ predicts that $\mathrm{S} \& \mathrm{P} 500$ stocks are expected to have, on average, lower limits of arbitrage relative to non-S\&P stocks. The fourth hypothesis $\left(\mathrm{H}_{4}\right)$ predicts that the S\&P 500 members are expected to have, on average, lower level of mispricing. Therefore, the parameter on the dummy variable $S \& P_{i t}\left(\delta_{1}\right)$ in equation (19) is expected to be negative. After that, the empirical investigation will explore the relationship between arbitrage risk on mispricing for S\&P 500 members compared to non-S\&P stocks. In order to conduct this analysis, I use the interaction dummy variable $\left(S \& P_{i t} \times A R_{i t}\right)$ to capture the incremental effect of $\mathrm{S} \& \mathrm{P} 500$ membership, arbitrage risk, and size on stock mispricing. Therefore, the parameter $\delta_{2}$ in equation (19) is expected to be different from zero. Furthermore, that information uncertainty effect on securities mispricing is expected to be lower for S\&P 500 stocks relative to non-S\&P stocks. Hence, in equation (19) I expect the parameter $\delta_{4}$ on the interaction term $\left(S \& P_{i t} \times C F V O L_{-} A T_{i t}\right)$ to be negative and statistically significant. Finally, I explore the effect of transaction costs on security mispricing for S\&P 500 members relative to non-S\&P stocks. Therefore, in equation (19) I expect the parameter estimate $\delta_{6}$ on the interaction variable $\left(S \& P_{i t} \times B I D A S K_{i t}\right)$ to be negative and significant. 


\subsection{Estimation Methodology}

In order to investigate the effect of index membership and the limits of arbitrage on securities mispricing it is important to observe the behavior of mispricing over time to analyze the effect of the relevant variables that vary across firms and also vary over time. Panel data regression models specifically suits the analysis at hand because it combines a set of common cross-section units observed over time. In addition, panel data can be used to treat unobserved heterogeneity in the cross-section or time series units. Unobserved heterogeneity is an unmeasured exogenous variable that distinguishes the behavior of each cross-section unit or each time period. Excluding these variables from the regression model will produce biased parameters estimates if the omitted variables are not orthogonal to other variables.

Panel data models can be generally classified into Random Effects (RE) models and Fixed Effects (FE) Models. RE models assume that unobserved heterogeneity is randomly distributed across cross-section and/or time series units and it is captured in a random variable which is incorporated into the error term. On the other hand, the FE model is usually used when the panel data at hand is likely to have significant unobserved heterogeneity that can be represented as a simple parametric shifts of the regression line. Therefore, this unobserved heterogeneity is autonomous in nature and it can be captured by a simple linear intercept for each cross-section unit and/or time series unit. Another way to deal with unobserved heterogeneity in the FE model is by demeaning the independent variables by subtracting each observation from its average.

The RE model is generally preferred to the FE model because of the saving in degrees of freedom. However, in order to use the RE model the unobserved heterogeneity must be uncorrelated with the error term. Since we cannot observe either the error term or the unobserved effect, we cannot directly test the correlation between the two. As a proxy for this test, Hausman 
(1978) suggests a test that compares the parameter estimates of the FE (consistent estimate) and the RE (efficient estimate). If there is no significant difference between the two estimates, then the RE model is assumed to satisfy the necessary assumption and we use RE. However, if there is a significant difference between the two estimates, then FE is preferred to the RE model. The hypothesis of the Hausman test can be formally stated as:

$$
\begin{aligned}
& \mathrm{H}_{0}: \mathrm{RE} \text { is preferred over FE } \\
& \mathrm{H}_{\mathrm{a}} \text { : not } \mathrm{H}_{0}
\end{aligned}
$$

The test statistic have Chi square $\left(\chi_{(d f)}^{2}\right)$ distribution with degrees of freedom equal to the rank of the number of estimated slopes.

After I run the Hausman test for the models presented in equations (18) and (19), the null hypothesis can be comfortably rejected at the $99 \%$ significance level $\left(\chi_{(8)}^{2}=165.79\right.$ and $\chi_{(18)}^{2}=180.55$, respectively). This result indicates that the FE model is best suited for this example. 


\section{CHAPTER 5}

\section{DATA AND EMPIRICAL RESULTS}

\subsection{Data}

The sample in this study consists of U.S. firms with available data in Compustat, Compustat-Index Constituents, the Center for Research in Security Prices (CRSP) and CRSP/Compustat Merged database during the period from 1982 to 2012. In addition, the Fama and French 3-factors are obtained from the Fama and French \& Liquidity Factors database. The choice of 1982 as a starting date for the sample is the availability of data needed to construct all the dependent variables. The initial sample consist of 8,592 firms (66,172 firm-years) with 664 firms (6,253 firm-years) included in the S\&P 500. After that, I remove all firms with negative dividends payout ratios. The final sample consists of 8,334 firms (62,339 firm-years) in which 661 firms (6,212 firm-years) are (were) S\&P 500 members. Furthermore, all independent variables are winsorized at the $1^{\text {st }}$ and the $99^{\text {th }}$ percentiles to reduce the effect of outliers and potential data recording errors.

\subsection{Descriptive Statistics and Empirical Results}

\subsubsection{Descriptive Statistics}

Table 1 shows the time-series average of the coefficients obtained from estimating equation (6) for each industry-year for the 12 Fama and French industries over the period 1982-2012. The reported estimates are consistent with results presented in Rhodes-Kropf et al. (2005) and Hertzel and $\mathrm{Li}$ (2010). Book value and net income are positively correlated with market value while having a negative net income, and leverage has negative impact on market value across all industries. In addition, the table reports the time-series average of the adjusted $\mathrm{R}^{2}$ for the estimated regression, 
which ranges from $88 \%$ to $95 \%$. This indicates that accounting information and market leverage ratio explain most of the cross-sectional variability for each of the Fama and French 12 industries.

[Insert Table 1 here]

Table 2 shows the time series average of the magnitude of mispricing of each of the Fama and French 12 industries obtained by estimating equation (17). The industry with the highest average and standard deviation of mispricing is the finance industry $\left(\left|M i s_{i t}\right|=0.61\right)$ which may arise because of the opaqueness of this industry. On the other hand, the industry with lowest average mispricing and standard deviation is the utilities industry $\left(\left|M i s_{i t}\right|=0.18\right)$. This may indicate that this industry is highly predictable because of its stable earnings stream that results from the high regulation on utilities pricing power.

[Insert Table 2 here]

Table 3 displays the time series average of the logit regression model, equation (17), estimated to obtain the propensity scores that are used to construct the proximity score. This equation is estimated for each industry-year over the sample period. The results show that the Psuedo- $\mathrm{R}^{2}$, which measures the goodness of fit of the logit model, is greater than 0.5 for 10 out of the 12 industries. This indicates that the model has a reasonably good fit. It is also important to note that the parameter estimates for the logit regression model do not directly measure the effect of the independent variable on the choice variable. Instead, the parameter estimates represent the effect of the independent variable on the "likelihood" of the choice variable to occur. In addition, the marginal effects of a given control variable in a non-linear models, such as the logit model, are different for each value of the control variables.

[Insert Table 3 here] 
The summary statistics of the sample in hand are provided in table 4. More importantly, Table 5 shows the time series average of the control variables for each industry. The industry that has the highest exposure to arbitrage risk is the healthcare industry $\left(A R_{i t}=0.08\right)$. This result indicates that the healthcare industry is more vulnerable to idiosyncratic shocks relative to other industries. On the other hand, the utilities industry shows the lowest level of idiosyncratic volatility $\left(A R_{i t}=0.03\right)$. Regarding size, the industry with the highest average size is the utilities industry $\left(S I Z E_{i t}=20.64\right)$, while the industry with the lowest average size is the finance industry $\left(S I Z E_{i t}=18.78\right)$. Furthermore, the healthcare industry shows the highest average volatility of cash flows relative to other industries $\left(C F V O L_{-} A T_{i t}=0.10\right)$, whereas the utilities industry has the lowest variability in cash flows $\left(C F V O L_{-} A T_{i t}=0.01\right)$. These results, indicate that there is a wide range of information uncertainty and information production between industries.

\section{[Insert Table 4 here]}

In addition, the industry with the highest ownership concentration is the telecom and TV industry, while the utilities show the lowest level of ownership concentration. In terms of transaction costs, the time series average of the bid-ask spread shows that most industries have, on average, similar levels of transaction costs $\left(B I D A S K_{i t}=0.03\right)$. However, the utilities industry shows a lower average level of transaction costs relative to other industries $\left(B I D A S K_{i t}=0.01\right)$. The average payout ratio, on the other hand, is highest for the finance industry $\left(D P O_{i t}=0.28\right)$ while the lowest average payout ratio belongs to the healthcare industry $\left(D P O_{i t}=0.12\right)$.

More importantly, the average proximity score, which measures the availability of substitutes, is highest for the chemicals industry and lowest for the computer and software industry $\left(\operatorname{Prox}_{i t}=9.7 \times 10^{-4}\right.$, and $\operatorname{Prox}_{i t}=0.01$; respectively $)$. In terms of financial constraints, which is 
measured by the absolute value of skewness, the healthcare industry shows the highest level of average absolute skewness $\left(\left|S k e w_{i t}\right|=0.96\right)$. On the other hand, the industry that shows the lowest level of the financial constraints is the utilities industry $\left(\mid\right.$ Skew $\left._{i t} \mid=0.50\right)$.

[Insert Table 5 here]

\subsubsection{Empirical Results}

Table 6 shows the parameters estimates obtained from estimating equation (18). The dependent variable in this regression model is the absolute value of mispricing, $\left|M i s_{i t}\right|$, Consistent with the theoretical framework of Shleifer and Vishny (1997) and the empirical results of Pontiff (1996) arbitrage risk has a significant positive impact on the magnitude of mispricing (tvalue $=8.14)^{14}$. Recall that arbitrage risk is measured as the standard deviation of the error term of the Fama and French 3-factors model. This variable captures the holding cost and the probability that price does not converge to fundamental value. ${ }^{15}$ On the other hand, the parameter estimate on the $S I Z E_{i t}$ is negative and statistically significant (t-value=-7.38). This result is consistent with the findings of Wurlger and Zhuravskaya (2002). Their results show that size is negatively related to the abnormal return associated with adding a stock to the S\&P 500. In addition, Loughran and Ritter (2000) indicate that almost every stock market anomaly is stronger for small stocks relative to large stocks.

[Insert Table 6 here]

Information uncertainty, measured by cash flow volatility (Zhang, 2006; and Lam et al., 2011), has a positive relationship with stock mispricing. The parameter estimate is positive and

\footnotetext{
14 The $5 \%$ one-tail critical value of the $t$-distribution $=1.645$

${ }^{15}$ I also measure the arbitrage risk as the standard deviation of the error term of the market model and the results are similar to the tabulated results.
} 
statistically significant at the $1 \%$ level (t-value=5.25). Zhang (2006) shows that momentum (shortterm price continuation) post-earnings price drift is more pronounced in stocks with higher cash flow volatility. In addition, ownership concentration has a statistically significant but economically insignificant effect on mispricing.

The parameter estimate on $B I D A S K_{i t}$, which measures transaction costs, is positive and statistically significant (t-value=4.87). Consistent with previous literature, transaction costs are positively associated with the magnitude of mispricing because it reduces the profitability of the arbitrage opportunity (Garman and Ohlson, 1981; and Pontiff, 1996). Dividend payout has a positive effect on mispricing, which is inconsistent with the findings of Pontiff (1996).

Consistent with the prediction of the availability of substitutes hypothesis $\left(\mathrm{H}_{1}\right)$, the relationship between the proximity score $\left(\operatorname{Prox}_{i t}\right)$ and stock mispricing is positive and statistically significant $(\mathrm{t}$-value=3.41). This result provides empirical evidence on the argument of Shleifer and Summers (1990), which states that securities in markets with less substitutes are expected to have higher mispricing components. Therefore, arbitrage is no more a risk-free activity. In addition, the result is also consistent with the Shleifer and Vishny (1997) world which indicates that specialized arbitrageurs are narrowly focused in the market in which they operate. This in turn limits the ability of arbitrageurs to identify securities with the same characteristics in other sectors. In addition, table 5 presents three different models: model (2), model (3), and model (4). These models are estimated using equation (18); but instead of using the closest match to calculate the proximity score, I use the closest five, ten and fifteen matches, respectively. These results indicate that even if the 
arbitrageur increases the size of his portfolio to include several stocks, the effect of the availability of substitutes persists. ${ }^{16}$

Recall that the financial constraints hypothesis $\left(\mathrm{H}_{2}\right)$ states that financially constrained arbitrageurs face an agency problem which makes them more sensitive to negative shocks that may affect the value of their portfolio. This sensitivity arises because arbitrageurs are risk averse and capital providers may force them to engage in a fire sale to recover their capital. Therefore, arbitrageurs are expected to prefer stocks with a more symmetrical distribution to minimize the higher probability of undesirable outcomes of skewed return distributions. Consistent with the second hypothesis, the parameter estimate on the proxy of financial constraints, $\mid$ Skew $w_{i t} \mid$, is positive and statistically significant $(\mathrm{t}-\mathrm{value}=2.16)$. This result is in line with arguments of Shleifer and Vishny (1997), Liu and Longstaff (2004), and Stein (2009).

In order to test for the difference in the limits of arbitrage between S\&P 500 members and non-S\&P 500 stocks, table 7 displays descriptive statistics of the independent variables for the two groups. More importantly the univariate tests of differences in means and medians of the limits of arbitrage between the two groups over the sample period are presented in table 8 . The results show that non-S\&P 500 stocks have significantly higher arbitrage risk $\left(A R_{i t} \mathrm{t}\right.$-value=110.53), greater cash flow volatility $\left(C F V O L_{-} A T_{i t} \mathrm{t}-\mathrm{value}=47.87\right)$, high transaction costs $\left(B I D A S K_{i t} \mathrm{t}-\right.$ value $=139.81)$, more ownership concentration $\left(O w n_{-}\right.$Conc $_{i t} \mathrm{t}$-value=9.55), higher skewness $\left(\mid\right.$ Skew $_{i t} \mid \mathrm{t}$-value $\left.=23.51\right)$, and more substitutes $\left(\operatorname{Prox}_{i t}=-61.20\right)$ relative to $\mathrm{S} \& \mathrm{P} 500$ stocks. On the other hand, S\&P 500 stocks higher market value $\left(\right.$ Size $_{i t} \mathrm{t}$-value $\left.=-2.2 \times 10^{2}\right)$, and greater dividends payout ratio $\left(D P O_{i t} \mathrm{t}-\mathrm{value}=-34.86\right)$.

\footnotetext{
${ }^{16}$ In addition to the presented models, I calculated the proximity score based on the twenty closest matches and the outcome is similar to the reported results.
} 
These results indicate that S\&P 500 stocks have, on average, lower limits of arbitrage, which is consistent with the prediction of difference in the limits of arbitrage hypothesis $\left(\mathrm{H}_{3}\right)$. Recall that previous studies suggest that the S\&P inclusion effect is associated with changes in several characteristics such as: liquidity (Erwin and Miller, 1998), information asymmetries (Denis et al., 2003), volatility (Lin, 2007), and transaction costs (Hedge and McDermott, 2003).

[Insert Table 7 here]

[Insert Table 8 here]

Table 9 displays the average magnitude of mispricing, and the univariate tests for the difference in mean and median in the magnitude of mispricing between non-S\&P 500 stocks and S\&P 500 members by industry. The results show that S\&P 500 stocks have, on average, lower mispricing as shown by the t-test relative to non-S\&P stocks. This result also holds for 8 out of the 12 Fama and French industries. In addition, there is no significant difference in the magnitude of mispricing in two industries, namely: utilities and others. The industry with the highest difference mispricing is the telecom and TV industry ( $\mathrm{t}$-value=0.61). On the other hand, the utilities and others industries show the lowest difference in mispricing ( $\mathrm{t}$-value $=-0.09$ and $\mathrm{t}-\mathrm{v}$ alue $=-0.36$, respectively).

[Insert Table 9 here]

Table 10 presents the parameter estimates obtained from estimating equation (19), model (1), using the magnitude of mispricing $\left(\left|M i s_{i t}\right|\right)$ as the dependent variable. The table also shows the estimates of different variations of equation (19) for the full sample without the dummy variables. In addition, the table shows the coefficients of the modified model for the non-S\&P 500 stocks and S\&P 500 members, respectively. The parameter estimate on the dummy variable 
$\left(S \& P_{i t}\right)$ is negative and statistically significant $(\mathrm{t}$-value=-4.39). This result supports the hypothesis that S\&P 500 members have, on average, lower mispricing relative to non-S\&P 500 stocks.

In addition, the incremental effect of arbitrage risk on S\&P 500 stocks mispricing is positive and statistically significant $(\mathrm{t}-\mathrm{value}=6.65)$. This result may arise because $\mathrm{S} \& \mathrm{P} 500$ stocks are efficiently price and the marginal cost of eliminating an extra unit of mispricing is relatively high (Grossman and Stiglitz, 1980).

\section{[Insert Table 10 here]}

The estimated model suggests that information uncertainty, as measured by cash flow volatility, has a positive effect on security mispricing for non-S\&P 500 stocks (Lam and Wei, 2011). However, the estimated coefficient on the interaction variable $\left(S \& P_{i t} \times C F V O L_{-} A T_{i t}\right)$ is not statistically significant. This result indicates that information uncertainty has no incremental effect on S\&P 500 stocks over/below non-S\&P 500 stocks. This may arise because of the additional media attention and analysts coverage that is devoted to S\&P 500 members overcomes any information content in cash flow volatility.

The estimated parameters show that transaction costs, as measured by the bid-ask spread, are positively related to firm specific mispricing. As transaction costs increase, $\mathrm{CP}$, it becomes more expensive for arbitrageurs to eliminate mispricing. Moreover, the estimated coefficient on the interaction variable $\left(S \& P_{i t} \times B I D A S K_{i t}\right)$ is negative but it is not statistically different from zero. $^{17}$

\footnotetext{
${ }^{17}$ Pearson correlation coefficients are presented in Table 11.
} 


\section{CHAPTER 6}

\section{CONCLUSION}

This paper contributes to the literature of the broad subject of mispricing by providing some evidence that price may deviate from fundamental value within the rational paradigm. Moreover, this study examines the effect of the limits of arbitrage for a large sample of more than 62,339 firm-years. In addition, this study adds to the limits of arbitrage and the arbitrage costs literature by constructing a variable to measure the availability of substitutes, which is the proximity score. In addition, this study examines the effect of the arbitrageurs' financial constraints on stock mispricing. Also, this study investigates the difference in the limits of arbitrage between S\&P 500 members and non-S\&P 500 stocks. Moreover, I empirically examine the relative mispricing of S\&P 500 members and non-S\&P 500 stocks.

After decomposing the market to book ratio, using the Rhodes-Kropf et al. (2005) methodology, into firm specific mispricing, sector mispricing, and long term growth component, I use the first component to investigate the question at hand. The empirical results support that hypothesis that the availability of substitutes affects the ability of arbitrageurs to eliminate

mispricing. This finding is consistent with the arguments of Shleifer and Summers (1990) and Shleifer and Vishny (1997). Also, this result may help to understand the S\&P 500 inclusion effect by providing support to the findings of Shleifer (1986) and Kaul et al. (2000) that indicate that stocks have a downward sloping demand curve. In other words, stocks may represent "a unique work of art".

Moreover, the results provide evidence that financially constrained arbitrageurs prefer stocks with more symmetrical distributions over stocks with skewed distributions to reduce the probability of liquidating their portfolios prematurely. This result supports the argument that 
agency problem that arises from the separation between arbitrageurs and capital may affect their ability to eliminate or reduce mispricing (Shleifer and Vishny, 1997; Liu and Longstaff, 2004; and Stein, 2009).

The univariate analysis indicates that S\&P 500 stocks have, on average, lower limits of arbitrage relative to non-S\&P stocks. In addition, multivariate test show that S\&P 500 members have lower mispricing relative to non-S\&P 500 stocks over the sample period.

In addition, the study provides evidence that arbitrage risk and has a significantly higher effect on mispricing for S\&P 500 members relative to non-S\&P 500 stocks. This result indicates that it is more risky to eliminate mispricing from S\&P 500 members because the marginal cost of reducing more efficiently priced stock is relatively higher. This finding is consistent with the merit of the argument of Grossman and Stiglitz (1980).

On the other hand, I find no significant evidence to support the hypothesis that information uncertainty has a lower effect on stock mispricing for S\&P 500 stocks. As mentioned earlier, the S\&P 500 is a widely followed index by media, analysts, and fund managers. This intense coverage for this group of stocks may significantly reduce the information uncertainty or the information content in cash flow volatility. Furthermore, I found no significant reduction of the effect of transaction costs on the magnitude of mispricing for S\&P 500 stocks compared to the other stocks in the sample.

This paper will be of a particular interest to researchers who are interested in understanding the market frictions and market factors that affect informational efficiency. In addition, this study may also interest practitioners and investment professionals who devote a lot of resources in an attempt to find mispriced securities to earn positive abnormal returns. Finally, this research might 
attract the attention of legislators who are looking for means to improve resource allocation and economic efficiency. 
Figure 1: Average Annual Mispricing 1982-2012

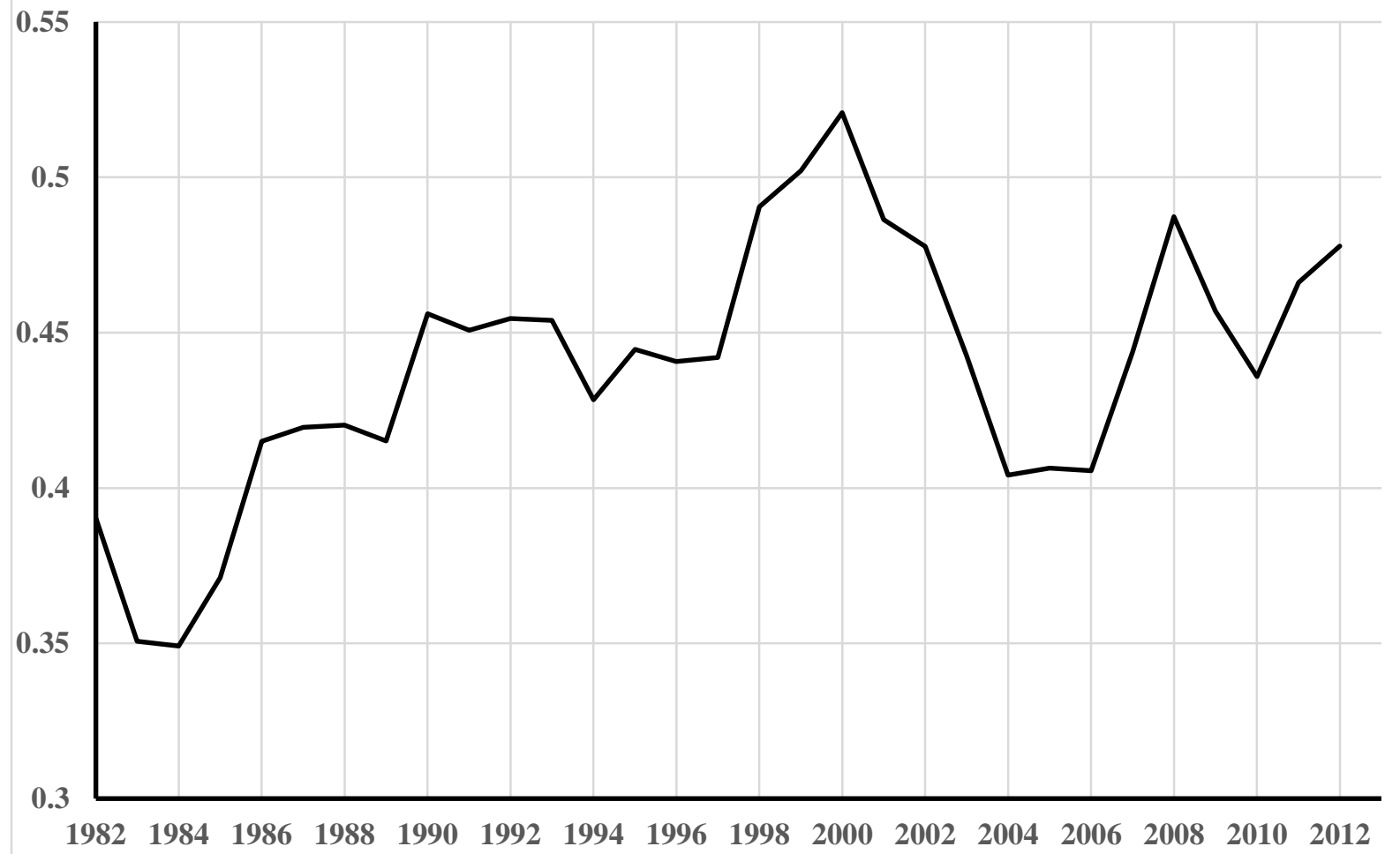


Table 1

Time Series Average Conditional Regression Coefficients (Rhodel Kropf et al. (2005) Parameters) by Industry

Table 1 presents the time-series average of the parameters, $E_{t}\left(\hat{\alpha}_{k j t}\right)$, estimated from equation (13) for the 12 Fama and French industries for the fiscal years 1982-2012. The dependent variable is the natural log of the market value $\left(\mathrm{m}_{\mathrm{t}}\right)$. The control variables are: (1) the natural $\log$ of the book value of equity $\left(b_{i t}\right)$ (item \#60), (2) the natural log of the absolute value of the net income $\left(n i_{i t}^{+}\right)$(item \#172), (3) a dummy variable that equals 1 if the net income is negative and 0 otherwise $\left(I_{(N I<0)} n i_{i t}^{+}\right)$, and (4) market value leverage ratio $\left(L E V_{i t}\right)$, where $L E V=1-(\mathrm{MVE} / \mathrm{MVA})=1$-(closing pricexcommon shares outstanding/ closing pricexcommon shares outstanding +total assests-deffered taxes-book value of equity) or LEV=1-(item \#199xitem \#25/ item \#199xitem \#25+ item \#6-item \#74-item\#60). The reported standard error is the average standard error for each parameter over the sampling period. The average Adjusted $\mathrm{R}^{2}$ is also reported for each industry.

$$
\text { (11) } m_{t}=\alpha_{0 j t}+\alpha_{1 j t} b_{i t}+\alpha_{2 j t} n i_{i t}^{+}+\alpha_{3 j t} I_{(N I<0)} n i_{i t}^{+}+\alpha_{4 j t} L E V_{i t}+\varepsilon_{i t}
$$

Fama and French Industry Classification

\begin{tabular}{|c|c|c|c|c|c|c|c|c|c|c|c|c|}
\hline 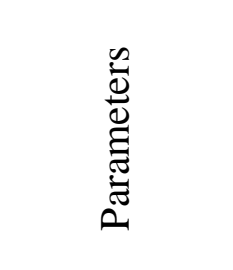 & 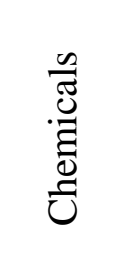 & 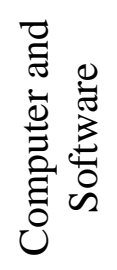 & 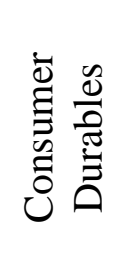 & 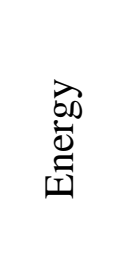 & 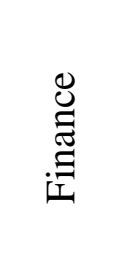 & 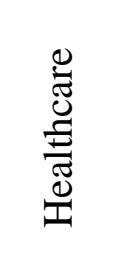 & 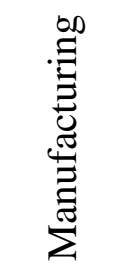 & 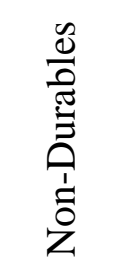 &  & $\stackrel{\mathscr{0}}{:}$ & $\begin{array}{l}\frac{0}{\pi} \\
\frac{0}{0} \\
\frac{0}{2} \\
\frac{1}{3}\end{array}$ & $\stackrel{\dot{\Xi}}{\overrightarrow{0}}$ \\
\hline$E_{t}\left(\hat{\alpha}_{0}\right)$ & 1.66 & 2.51 & 1.87 & 1.84 & 2.34 & 2.96 & 1.68 & 1.45 & 2.96 & 2.00 & 2.37 & 2.52 \\
\hline$S E$ & 1.13 & 0.71 & 1.10 & 0.94 & 0.58 & 0.96 & 0.78 & 0.77 & 0.54 & 0.88 & 0.43 & 0.57 \\
\hline$E_{t}\left(\hat{\alpha}_{1}\right)$ & 0.65 & 0.69 & 0.68 & 0.76 & 0.63 & 0.61 & 0.71 & 0.68 & 0.64 & 0.79 & 0.69 & 0.68 \\
\hline$S E$ & 0.11 & 0.07 & 0.10 & 0.08 & 0.07 & 0.07 & 0.06 & 0.07 & 0.09 & 0.18 & 0.05 & 0.06 \\
\hline$E_{t}\left(\hat{\alpha}_{2}\right)$ & 0.37 & 0.28 & 0.32 & 0.23 & 0.35 & 0.35 & 0.30 & 0.35 & 0.32 & 0.20 & 0.29 & 0.29 \\
\hline$S E$ & 0.09 & 0.04 & 0.09 & 0.06 & 0.06 & 0.05 & 0.05 & 0.06 & 0.09 & 0.16 & 0.04 & 0.04 \\
\hline$E_{t}\left(\hat{\alpha}_{3}\right)$ & -0.01 & -0.01 & -0.01 & -0.01 & -0.02 & -0.02 & -0.01 & -0.02 & -0.01 & -0.01 & -0.02 & -0.02 \\
\hline$S E$ & 0.01 & 0.01 & 0.01 & 0.01 & 0.01 & 0.01 & 0.01 & 0.01 & 0.02 & 0.03 & 0.01 & 0.01 \\
\hline$E_{t}\left(\hat{\alpha}_{4}\right)$ & -1.57 & -2.11 & -1.68 & -1.28 & -1.19 & -2.02 & -1.64 & -1.69 & -1.45 & -1.47 & -1.83 & -1.73 \\
\hline$S E$ & 0.53 & 0.47 & 0.36 & 0.36 & 0.28 & 0.44 & 0.33 & 0.31 & 0.47 & 0.56 & 0.24 & 0.23 \\
\hline Adjusted $\mathrm{R}^{2}$ & 0.93 & 0.88 & 0.92 & 0.92 & 0.88 & 0.87 & 0.91 & 0.92 & 0.90 & 0.95 & 0.91 & 0.87 \\
\hline $\mathrm{T}$ & 31 & 31 & 31 & 31 & 31 & 31 & 31 & 31 & 31 & 31 & 31 & 31 \\
\hline
\end{tabular}




\section{Table 2}

Time Series Average of Mispricing by Industry

Table 2 shows the summary statistics of the mispricing measure obtained by estimating equation (16): $\left|M i s_{i t}\right|=\left|m_{i t}-v\left(B_{i t}, N I_{i t}, L E V_{i t} ; \hat{\alpha}_{0 t}, \hat{\alpha}_{1 t}, \hat{\alpha}_{2 t}, \hat{\alpha}_{3 t}, \hat{\alpha}_{4 t}\right)\right|$, for each industry-year over the sample period 1982-2012 and calculating the time series average of the magnitude of mispricing for each of the Fama and French 12 industries.

\begin{tabular}{lccccc}
\hline \multicolumn{1}{c}{ Industry } & $\mathrm{N}$ & Mean & $\begin{array}{c}\text { Standard } \\
\text { Deviation }\end{array}$ & Min & Max \\
\hline Chemicals & 1,885 & 0.43 & 0.39 & $2.86 \times 10^{-5}$ & 3.96 \\
Computer and Software & 13,360 & 0.48 & 0.40 & $5.72 \times 10^{-6}$ & 5.86 \\
Consumer Durables & 2,021 & 0.41 & 0.38 & $1.47 \times 10^{-4}$ & 3.25 \\
Energy & 3,085 & 0.41 & 0.40 & $2.82 \times 10^{-4}$ & 3.05 \\
Finance & 1,947 & 0.61 & 0.61 & $7.80 \times 10^{-4}$ & 5.44 \\
Healthcare & 6,793 & 0.51 & 0.44 & $8.96 \times 10^{-5}$ & 4.49 \\
Manufacturing & 8,471 & 0.41 & 0.38 & $1.41 \times 10^{-4}$ & 5.50 \\
Non-Durables & 4,394 & 0.47 & 0.42 & $5.91 \times 10^{-5}$ & 6.60 \\
Telecom and TV & 1,454 & 0.54 & 0.52 & $2.70 \times 10^{-4}$ & 5.40 \\
Utilities & 2,630 & 0.18 & 0.23 & $4.12 \times 10^{-4}$ & 2.84 \\
Wholesale & 7,724 & 0.41 & 0.37 & $2.86 \times 10^{-5}$ & 4.55 \\
Other & 8,575 & 0.49 & 0.44 & $8.96 \times 10^{-5}$ & 4.47 \\
\hline Total & 62,339 & 0.45 & 0.42 & $5.72 \times 10^{-6}$ & 6.59 \\
\hline
\end{tabular}


Table 3

Time Series Average of the Logit Regression Coefficients by Industry

Table 3 presents the time-series average of the parameters, $E_{t}\left(\hat{\gamma}_{k j t}\right)$, estimated from equation (17) for the 12 Fama and French industries for the fiscal years 1982-2012. The dependent variable is a binary variable that equals 1 if the company is included in the S\&P 500 and 0 if not. The control variables are: (1) the beta of stock $i$ at time $t$, (2) size measured as the natural log of the market value of equity, (3) and book-to-market ratio. The reported standard error is the average standard error for each parameter over the sampling period. The average Psuedo- $\mathrm{R}^{2}$ also is reported for each industry.

(17) $P^{*}=\gamma_{0}+\gamma_{1} \beta_{i t}+\gamma_{2}$ Size $_{i t}+\gamma_{3} B M_{i t}+\varepsilon_{i t}$

Fama and French Industry Classification

\begin{tabular}{|c|c|c|c|c|c|c|c|c|c|c|c|c|}
\hline 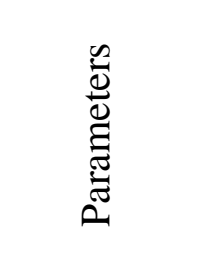 & $\begin{array}{l}\frac{n}{\pi} \\
. \frac{U}{d} \\
\frac{d}{U}\end{array}$ & 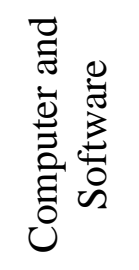 & 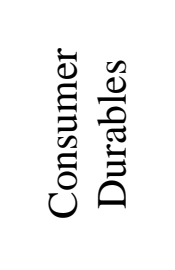 & 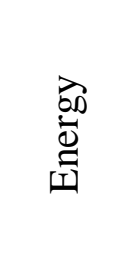 & $\underset{\Xi}{\stackrel{\Xi}{\Xi}}$ & 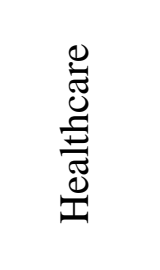 & 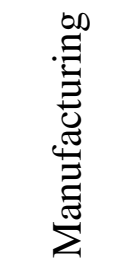 & 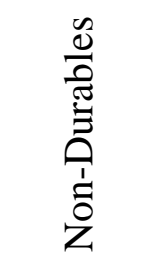 & 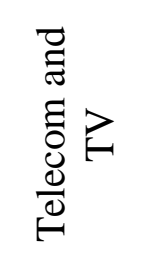 & : & $\begin{array}{l}\frac{0}{\tilde{J}} \\
\frac{0}{0} \\
\frac{0}{2} \\
\frac{1}{3}\end{array}$ & $\begin{array}{l}\dot{\Phi} \\
\stackrel{\Xi}{0}\end{array}$ \\
\hline$E_{t}\left(\hat{\gamma}_{1}\right)$ & -50.13 & -51.70 & -1575.53 & -34.43 & -852.24 & -194.80 & -41.14 & -442.89 & -561.93 & -54.33 & -55.60 & -3688.25 \\
\hline$S E$ & 16.09 & 18.88 & 14.45 & 15.42 & 27.93 & 10.11 & 8.63 & 6.39 & 17.82 & 12.72 & 14.04 & 9.01 \\
\hline$E_{t}\left(\hat{\gamma}_{1}\right)$ & 0.54 & 0.63 & 20.00 & 1.20 & -19.70 & -0.43 & 0.93 & 49.24 & -40.08 & 4.43 & 0.64 & 150.93 \\
\hline$S E$ & 1.90 & 0.90 & 2.34 & 2.06 & 1.60 & 1.16 & 0.92 & 1.03 & 2.61 & 2.14 & 1.19 & 0.91 \\
\hline$E_{t}\left(\hat{\gamma}_{2}\right)$ & -0.79 & 0.49 & 124.21 & 0.51 & 91.94 & -127.79 & -0.06 & 31.76 & -119.09 & 2.30 & 1.07 & 139.06 \\
\hline$S E$ & 2.69 & 1.76 & 3.31 & 1.75 & 2.81 & 2.31 & 1.35 & 0.91 & 3.07 & 1.88 & 1.87 & 0.91 \\
\hline$E_{t}\left(\hat{\gamma}_{3}\right)$ & 2.26 & 2.33 & 75.57 & 1.49 & 38.16 & 10.26 & 1.83 & 17.97 & 27.79 & 2.25 & 2.46 & 168.47 \\
\hline$S E$ & 0.71 & 0.90 & 0.59 & 0.73 & 1.25 & 0.43 & 0.39 & 0.29 & 0.78 & 0.53 & 0.63 & 0.42 \\
\hline Psuedo-R ${ }^{2}$ & 0.64 & 0.63 & 0.44 & 0.42 & 0.71 & 0.66 & 0.56 & 0.63 & 0.67 & 0.54 & 0.63 & 0.56 \\
\hline $\mathrm{T}$ & 21 & 29 & 26 & 28 & 15 & 25 & 26 & 30 & 21 & 22 & 28 & 29 \\
\hline
\end{tabular}


Table 4

Summary Statistics for the Full Sample

\begin{tabular}{|c|c|c|c|c|c|c|c|}
\hline Variable & Mean & $\begin{array}{l}\text { Standard } \\
\text { Deviation }\end{array}$ & Min & Max & $10 \%$ & $50 \%$ & $90 \%$ \\
\hline$\left|M i s_{i t}\right|$ & 0.45 & 0.42 & $5.72 \times 10^{-6}$ & 6.61 & 0.06 & 0.34 & 0.97 \\
\hline$A R_{i t}$ & 0.05 & 0.04 & 0.02 & 0.23 & 0.03 & 0.06 & 0.12 \\
\hline$S I Z E_{i t}$ & 19.11 & 2.21 & 14.70 & 24.61 & 16.31 & 18.96 & 22.10 \\
\hline CFVOL_AT $i t$ & 0.07 & 0.12 & $2.19 \times 10^{-3}$ & 0.86 & 0.007 & 0.03 & 0.16 \\
\hline Own_Conc $i t$ & 58,866 & 162,265 & 602.52 & $1,148,411$ & 1,746 & 8,666 & 132,406 \\
\hline$B I D A S K_{i t}$ & 0.03 & 0.04 & $3.14 \times 10^{-4}$ & 0.25 & $1.1 \times 10^{-3}$ & 0.02 & 0.08 \\
\hline$D P O_{i t}$ & 0.19 & 0.36 & 0 & 2.28 & 0 & 0.04 & 0.52 \\
\hline $\operatorname{Prox}_{i t}$ & 0.002 & 0.0054 & 0 & 0.035 & $1.4 \times 10^{-7}$ & $4 \times 10^{-5}$ & 0.01 \\
\hline $\mid$ Skew $_{i t} \mid$ & 0.77 & 0.90 & 0.007 & 5.40 & 0.09 & 0.49 & 1.71 \\
\hline
\end{tabular}


Table 5

Time Series Average of Variables by Industry

Table 5 presents the time series average of the dependent variable, $\left|M i s_{i t}\right|$, and the control variables by industry over the sample period (1982-2012). All variables are winsorized at the $1^{\text {st }}$ and the $99^{\text {th }}$ percentiles.

Fama and French Industry Classification

\begin{tabular}{|c|c|c|c|c|c|c|c|c|c|c|c|c|}
\hline $\begin{array}{l}\frac{0}{\pi} \\
. \frac{\pi}{\tilde{\sigma}} \\
>\end{array}$ & 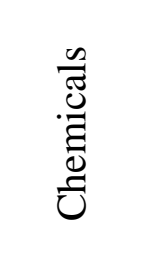 & 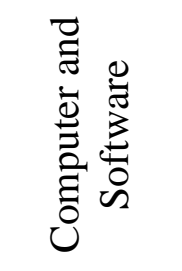 & 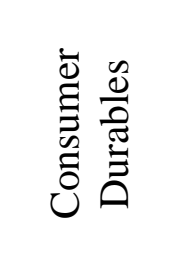 & 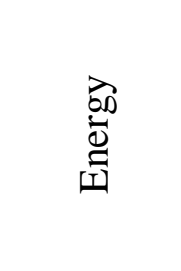 & 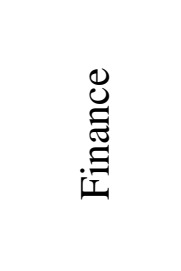 & 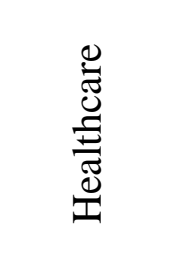 & 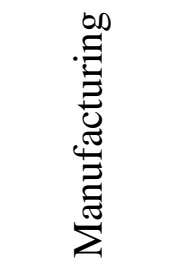 & 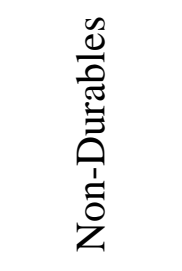 & 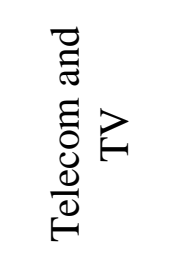 & 苛 &  & $\begin{array}{l}\overline{\breve{v}} \\
\bar{\Xi}\end{array}$ \\
\hline$\left|M i s_{i t}\right|$ & 0.43 & 0.47 & 0.41 & 0.41 & 0.57 & 0.50 & 0.46 & 0.46 & 0.52 & 0.18 & 0.41 & 0.48 \\
\hline$A R_{i t}$ & 0.05 & 0.07 & 0.06 & 0.06 & 0.07 & 0.08 & 0.06 & 0.06 & 0.06 & 0.03 & 0.06 & 0.07 \\
\hline$S I Z E_{i t}$ & 19.79 & 18.80 & 18.96 & 19.75 & 18.78 & 18.98 & 19.03 & 19.22 & 20.27 & 20.64 & 18.98 & 18.86 \\
\hline$C F V O L_{-} A T_{i t}$ & 0.05 & 0.11 & 0.05 & 0.06 & 0.09 & 0.10 & 0.05 & 0.05 & 0.07 & 0.01 & 0.04 & 0.06 \\
\hline Own_Conc $i t$ & 34,748 & 77,659 & 35,979 & 74,133 & 64,117 & 74,157 & 36,007 & 36,845 & 112,629 & 16,887 & 46,221 & 70,530 \\
\hline$B I D A S K_{i t}$ & 0.03 & 0.03 & 0.03 & 0.03 & 0.04 & 0.03 & 0.03 & 0.03 & 0.02 & 0.01 & 0.03 & 0.04 \\
\hline$D P O_{i t}$ & 0.23 & 0.19 & 0.17 & 0.12 & 0.28 & 0.12 & 0.18 & 0.22 & 0.18 & 0.26 & 0.17 & 0.16 \\
\hline $\operatorname{Prox}_{i t}$ & 0.01 & $9.7 \times 10^{-4}$ & $2.9 \times 10^{-2}$ & $3.4 \times 10^{-3}$ & $3.3 \times 10^{-3}$ & $1.6 \times 10^{-3}$ & $1.4 \times 10^{-3}$ & $2.6 \times 10^{-3}$ & $4.9 \times 10^{-3}$ & $4.2 \times 10^{-3}$ & $1.5 \times 10^{-3}$ & $1.2 \times 10^{-2}$ \\
\hline $\mid$ Skew $_{i t} \mid$ & 0.66 & 0.82 & 0.73 & 0.60 & 0.80 & 0.94 & 0.69 & 0.76 & 0.73 & 0.50 & 0.76 & 0.77 \\
\hline
\end{tabular}




\section{Table 6}

Mispricing and Limits of Arbitrage Regression

Table 6 shows parameter estimates for the one way fixed effect regression model for equation (13). Model (1) shows the results with the proximity score calculated for the nearest match, Model (2) shows the results for the average of the closest five matches, Model (3) shows the results for the average proximity score for the closest ten matches and Model (4) shows the results for the average of the closest 15 matches. The reported standard errors are robust standard errors adjusted for clustering by industry.

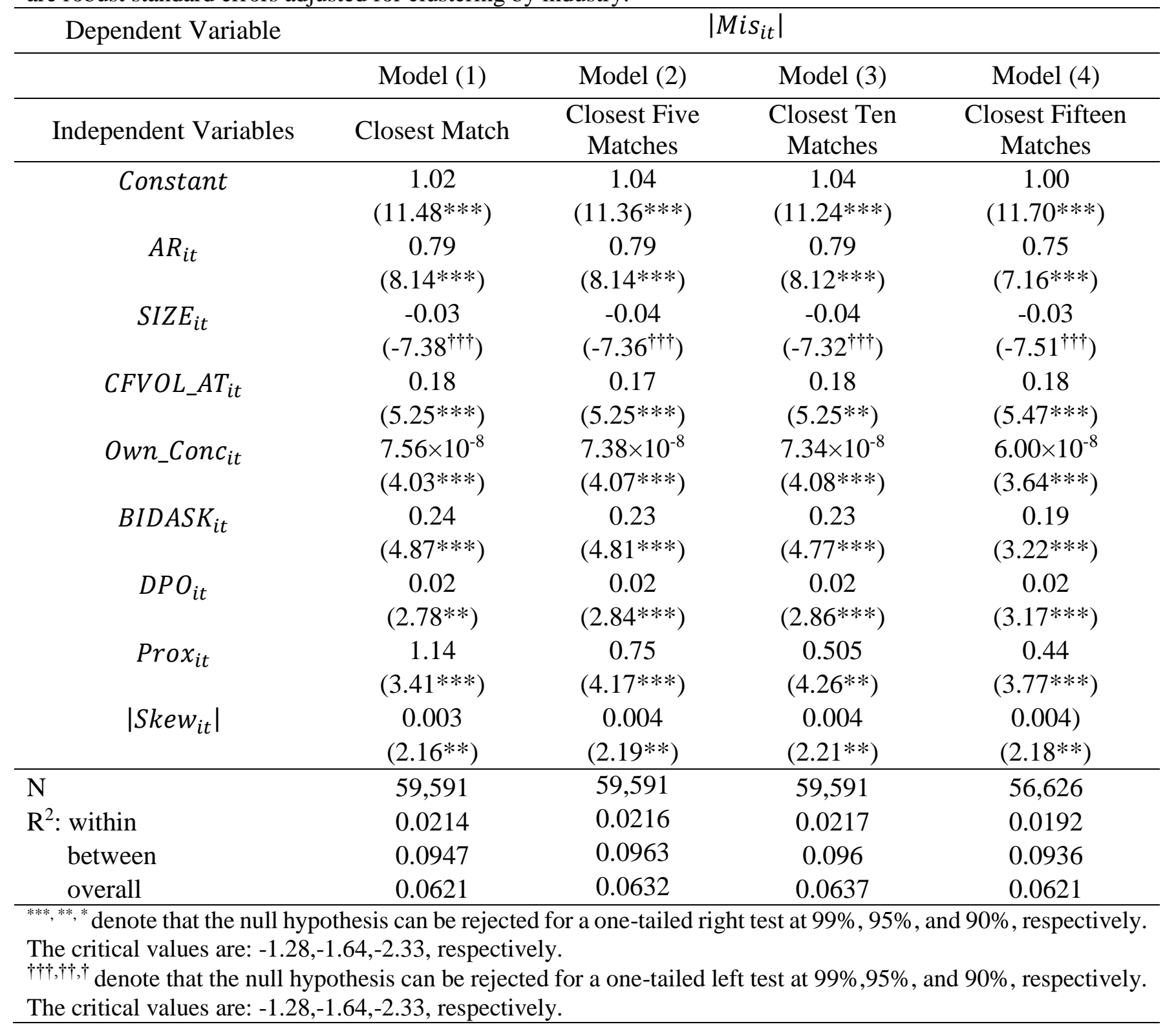




\section{Table 7}

Summary Statistics of Non-S\&P 500 Stocks and S\&P 500 Stocks

Table 7 shows the sample statistics of the dependent variable (absolute value of mispricing) and the independent variables for the winsorized variables at the $1^{\text {st }}$ and the $99^{\text {th }}$ percentiles. (Panel A) shows the summary statistics of the non-S\&P 500 stocks, while (Panel B) shows the summary statistics of the S\&P 500 members over the sample period (1982-2012)

$\begin{array}{lllllll}\text { Variable } & \text { Mean } & \begin{array}{c}\text { Standard } \\ \text { Deviation }\end{array} & \text { Min } & \text { Max } & 10 \% & 50 \%\end{array}$

\begin{tabular}{|c|c|c|c|c|c|c|c|}
\hline \multicolumn{8}{|c|}{ Panel A-Non S\&P 500 Stocks } \\
\hline$\left|M i s_{i t}\right|$ & 0.46 & 0.42 & $5.72 \times 10^{-6}$ & 6.61 & 0.06 & 0.35 & 0.97 \\
\hline$A R_{i t}$ & 0.07 & 0.4 & 0.02 & 0.23 & 0.03 & 0.06 & 0.12 \\
\hline$S I Z E_{i t}$ & 18.71 & 1.93 & 14.69 & 24.61 & 16.21 & 18.66 & 21.85 \\
\hline$C F V O L \_A T_{i t}$ & 0.07 & 0.13 & $2.16 \times 10^{-3}$ & 0.86 & $8.17 \times 10^{-3}$ & 0.03 & 0.17 \\
\hline Own_Conc $c_{i t}$ & 60,453 & 166,277 & 602 & $1,148,411$ & 1,722 & 8,531 & 290,864 \\
\hline$B I D A S K_{i t}$ & 0.04 & 0.06 & $3.14 \times 10^{-4}$ & 0.25 & $1.45 \times 10^{-3}$ & 0.02 & 0.09 \\
\hline$D P O_{i t}$ & 0.17 & 0.36 & 0 & 2.28 & 0 & 0.02 & 0.48 \\
\hline $\operatorname{Prox}_{i t}$ & $1.07 \times 10^{-3}$ & $3.91 \times 10^{-3}$ & 0 & 0.04 & $9.5 \times 10^{-8}$ & $2.4 \times 10^{-5}$ & $2.05 \times 10^{-3}$ \\
\hline $\mid$ Skew $_{i t} \mid$ & 0.79 & 0.92 & $7.84 \times 10^{-3}$ & 5.40 & 0.09 & 0.51 & 1.76 \\
\hline \multicolumn{8}{|c|}{ Panel B- S\&P 500 Stocks } \\
\hline$\left|M i s_{i t}\right|$ & 0.39 & 0.39 & $2.86 \times 10^{-5}$ & 4.2 & 0.05 & 0.28 & 0.86 \\
\hline$A R_{i t}$ & 0.04 & 0.2 & 0.02 & 0.22 & 0.02 & 0.03 & 0.06 \\
\hline$S I Z E_{i t}$ & 22.64 & 1.22 & 17.33 & 24.61 & 21.04 & 22.67 & 24.43 \\
\hline$C F V O L \_A T_{i t}$ & 0.03 & 0.05 & $2.19 \times 10^{-3}$ & 0.86 & $6.02 \times 10^{-3}$ & 0.02 & 0.06 \\
\hline Own_Conc $c_{i t}$ & 44,528 & 119,124 & 602 & $1,148,411$ & 1,989 & 9,639 & 98,616 \\
\hline$B I D A S K_{i t}$ & $6.4 \times 10^{-3}$ & $7.2 \times 10^{-3}$ & $3.14 \times 10^{-4}$ & 0.08 & $3.74 \times 10^{-3}$ & $4.11 \times 10^{-2}$ & 0.02 \\
\hline$D P O_{i t}$ & 0.33 & 0.34 & 0 & 2.28 & 0.02 & 0.24 & 0.70 \\
\hline $\operatorname{Prox}_{i t}$ & $8.92 \times 10^{-3}$ & $9.98 \times 10^{-3}$ & 0 & 0.04 & $4.33 \times 10^{-4}$ & $5.02 \times 10^{-3}$ & 0.03 \\
\hline $\mid$ Skew $_{i t} \mid$ & 0.55 & 0.71 & $7.84 \times 10^{-3}$ & 5.40 & 0.06 & 0.34 & 1.21 \\
\hline
\end{tabular}


Table 8

Non-S\&P 500 versus S\&P 500 Members: Comparison of Mean and Median of Dependent Variables

Table 8 shows the sample mean and median of the absolute value of mispricing over the sample period for the subsamples that consists of non-S\&P 500 stocks and S\&P 500 members. In addition, the table reports the t-test on the equality of means and Wilcoxon ranked test on the equality of medians.

\begin{tabular}{|c|c|c|c|c|c|c|c|c|}
\hline \multirow{3}{*}{ Variable } & \multicolumn{3}{|c|}{$\begin{array}{c}\text { Non-S\&P } 500 \text { Stocks } \\
\text { (1) }\end{array}$} & \multicolumn{3}{|c|}{$\begin{array}{l}\text { S\&P } 500 \text { Members } \\
\text { (2) }\end{array}$} & \multirow{2}{*}{\multicolumn{2}{|c|}{$\begin{array}{l}\text { Test of Differences } \\
\text { (1)-(2) }\end{array}$}} \\
\hline & \multirow{2}{*}{$\mathrm{N}$} & \multirow{2}{*}{ Mean } & \multirow{2}{*}{ Median } & \multirow{2}{*}{$\mathrm{N}$} & \multirow{2}{*}{ Mean } & \multirow{2}{*}{ Median } & & \\
\hline & & & & & & & t-statistic ${ }^{\dagger}$ & $\begin{array}{c}\text { Wilcoxon } \\
\text { Ranked Test }\end{array}$ \\
\hline$A R_{i t}$ & 56,141 & 0.07 & 0.06 & 6,212 & 0.04 & 0.03 & $110.53 * * *$ & $75.99 * * *$ \\
\hline$S I Z E_{i t}$ & 56,141 & 18.71 & 18.57 & 6,212 & 22.63 & 22.66 & $-2.2 \times 10^{2} * * *$ & $-117.67 * * *$ \\
\hline$C F V O L \_A T_{i t}$ & 56,141 & 0.07 & 0.03 & 6,212 & 0.03 & 0.02 & $47.87 * * *$ & $36.36 * * *$ \\
\hline Own_Conc $i t$ & 56,141 & 60,453 & 8,595 & 6,212 & 44,528 & 9,639 & $9.55 * * *$ & $-3.97 * * *$ \\
\hline$B I D A S K_{i t}$ & 56,141 & 0.04 & 0.02 & 6,212 & $6.4 \times 10^{-3}$ & $4.2^{-3}$ & $139.81 * * *$ & $77.95 * * *$ \\
\hline$D P O_{i t}$ & 56,141 & 0.17 & $3.810^{-3}$ & 6,212 & 0.33 & 0.25 & $-34.86 * * *$ & $-66.37 * * *$ \\
\hline $\operatorname{Prox}_{i t}$ & 53,413 & $1.07 \times 10^{-3}$ & $2.4 \times 10^{-5}$ & 6,178 & $8.92 \times 10^{-3}$ & $5.02 \times 10^{-3}$ & $-61.20 * * *$ & $-105.46^{* * *}$ \\
\hline $\mid$ Skew $_{i t} \mid$ & 56,127 & 0.79 & 0.51 & 6,212 & 0.55 & 0.34 & $23.51 * * *$ & $25.26 * * *$ \\
\hline
\end{tabular}


Table 9

Non-S\&P 500 versus S\&P 500 Members: Comparison of Mean and Median of the Absolute Value of Mispricing

Table 9 shows the sample mean and median of the absolute value of mispricing over the sample period for the subsamples that consists of non-S\&P 500 stocks and S\&P 500 members. In addition, the table reports the t-test on the equality of means and Wilcoxon ranked test on the equality of medians.

\begin{tabular}{|c|c|c|c|c|c|c|c|c|}
\hline \multirow{3}{*}{ Industry } & \multicolumn{3}{|c|}{$\begin{array}{c}\text { Non-S\&P } 500 \text { Stocks } \\
(1)\end{array}$} & \multicolumn{3}{|c|}{$\begin{array}{c}\text { S\&P } 500 \text { Members } \\
(2)\end{array}$} & \multirow{2}{*}{\multicolumn{2}{|c|}{$\begin{array}{l}\text { Test of Differences } \\
\text { (1)-(2) }\end{array}$}} \\
\hline & \multirow{2}{*}{$\mathrm{N}$} & \multirow{2}{*}{ Mean } & \multirow{2}{*}{ Median } & \multirow{2}{*}{$\mathrm{N}$} & \multirow{2}{*}{ Mean } & \multirow{2}{*}{ Median } & & \\
\hline & & & & & & & t-statistic ${ }^{\dagger}$ & $\begin{array}{c}\text { Wilcoxon } \\
\text { Ranked Test }\end{array}$ \\
\hline Chemicals & 1,536 & 0.44 & 0.33 & 349 & 0.40 & 0.26 & $1.64 *$ & $2.32 * *$ \\
\hline Computer and Software & 12,271 & 0.48 & 0.40 & 1,092 & 0.43 & 0.32 & $3.90 * * *$ & $4.74 * * *$ \\
\hline Consumer Durables & 1,897 & 0.41 & 0.31 & 124 & 0.51 & 0.34 & -2.17 & -1.34 \\
\hline Energy & 2,680 & 0.43 & 0.32 & 407 & 0.30 & 0.20 & $8.49 * * *$ & $6.90 * * *$ \\
\hline Finance & 1,822 & 0.61 & 0.47 & 125 & 0.50 & 0.47 & $3.17 * *$ & 0.63 \\
\hline Healthcare & 6,249 & 0.52 & 0.43 & 547 & 0.41 & 0.32 & $6.44 * * *$ & $5.71 * * *$ \\
\hline Manufacturing & 7,550 & 0.42 & 0.32 & 925 & 0.36 & 0.26 & $4.65 * * *$ & $4.60 * * *$ \\
\hline Non-Durables & 3,739 & 0.46 & 0.35 & 656 & 0.49 & 0.36 & -1.55 & -0.68 \\
\hline Telecom and TV & 1,238 & 0.58 & 0.44 & 216 & 0.32 & 0.21 & $9.65 * * *$ & $8.16 * * *$ \\
\hline Utilities & 2,064 & 0.18 & 0.12 & 566 & 0.18 & 0.12 & -0.09 & 0.60 \\
\hline Wholesale & 7,038 & 0.42 & 0.32 & 690 & 0.35 & 0.25 & $4.69 * * *$ & $4.99 * * *$ \\
\hline Other & 8,057 & 0.49 & 0.39 & 519 & 0.50 & 0.36 & -0.36 & 0.34 \\
\hline Total & 56,141 & 0.46 & 0.35 & 6,212 & 0.39 & 0.28 & $13.27 * * *$ & $15.46 * * *$ \\
\hline
\end{tabular}




\section{Table 10}

Magnitude of Mispricing Regression with S\&P 500 Dummies

Table 10 shows parameter estimates for the one way fixed effect regression model for equation (12). Models (2), (3), and (4) regress the magnitude of mispricing on the dependent variables for the full sample (with no dummy variables), non-S\&P 500 stocks, and S\&P 500 members, respectively. The standard errors are robust standard errors adjusted for clustering by industry.

\begin{tabular}{|c|c|c|c|c|}
\hline \multirow{2}{*}{$\begin{array}{c}\text { Dependent Variable } \\
\text { Independent Variables }\end{array}$} & \multicolumn{4}{|c|}{$\left|M_{i t}\right|$} \\
\hline & Model (1) & Model (2) & Model (3) & Model (4) \\
\hline Constant & $\begin{array}{c}1.13 \\
\left(12.58^{* * *}\right)\end{array}$ & $\begin{array}{c}1.02 \\
\left(11.48^{* * *}\right)\end{array}$ & $\begin{array}{c}1.14 \\
(13.67 * *)\end{array}$ & $\begin{array}{c}-0.27 \\
(-0.98)\end{array}$ \\
\hline$A R_{i t}$ & $\begin{array}{c}0.69 \\
(7.57 * * *)\end{array}$ & $\begin{array}{c}0.79 \\
(8.14 * * *)\end{array}$ & $\begin{array}{c}0.66 \\
\left(7.38^{* * *}\right)\end{array}$ & $\begin{array}{c}3.51 \\
\left(9.00^{* * *}\right)\end{array}$ \\
\hline$S I Z E_{i t}$ & $\begin{array}{c}-0.04 \\
(-8.30 * * *)\end{array}$ & $\begin{array}{c}-0.03 \\
\left(-7.38^{* * *}\right)\end{array}$ & $\begin{array}{c}-0.04 \\
(-9.01 * * *)\end{array}$ & $\begin{array}{c}0.02 \\
\left(1.93^{* *}\right)\end{array}$ \\
\hline$C F V O L \_A T_{i t}$ & $\begin{array}{c}0.17 \\
(5.64 * *)\end{array}$ & $\begin{array}{c}0.18 \\
\left(5.25^{* * *}\right)\end{array}$ & $\begin{array}{c}0.17 \\
(5.51 * * *)\end{array}$ & $\begin{array}{c}0.54 \\
(1.66)\end{array}$ \\
\hline Own_Conc $i t$ & $\begin{array}{l}9.29 \times 10^{-8} \\
(3.94 * * *)\end{array}$ & $\begin{array}{l}7.56 \times 10^{-8} \\
\left(4.03^{* * *}\right)\end{array}$ & $\begin{array}{l}9.66 \times 10^{-8} \\
\left(4.06^{* * *}\right)\end{array}$ & $\begin{array}{c}-2.10 \times 10^{-8} \\
(-0.23)\end{array}$ \\
\hline$B^{\prime D A S K} K_{i t}$ & $\begin{array}{c}0.21 \\
\left(3.65^{* *}\right)\end{array}$ & $\begin{array}{c}0.24 \\
(4.87 * * *)\end{array}$ & $\begin{array}{c}0.21 \\
\left(3.23^{* * *}\right)\end{array}$ & $\begin{array}{c}0.10 \\
(0.10)\end{array}$ \\
\hline$D P O_{i t}$ & $\begin{array}{c}0.01 \\
\left(2.01^{* *}\right)\end{array}$ & $\begin{array}{c}0.02 \\
(2.78 * *)\end{array}$ & $\begin{array}{c}0.01 \\
\left(2.18^{* *}\right)\end{array}$ & $\begin{array}{c}0.06 \\
\left(2.80^{* *}\right)\end{array}$ \\
\hline Prox $_{i t}$ & $\begin{array}{c}2.37 \\
(4.36 * * *)\end{array}$ & $\begin{array}{c}1.14 \\
\left(3.41^{* * *}\right)\end{array}$ & $\begin{array}{c}2.39 \\
\left(3.86^{* * *}\right)\end{array}$ & $\begin{array}{c}0.45 \\
(1.03)\end{array}$ \\
\hline $\mid$ Skew $_{i t} \mid$ & $\begin{array}{c}0.005 \\
(2.56 * * *)\end{array}$ & $\begin{array}{c}0.003 \\
\left(2.16^{* *}\right)\end{array}$ & $\begin{array}{c}0.005 \\
(2.57 * * *)\end{array}$ & $\begin{array}{c}-0.01 \\
(-0.93)\end{array}$ \\
\hline$S \& P_{i t}$ & $\begin{array}{c}-1.27 \\
(-4.39 * * *)\end{array}$ & & & \\
\hline$\left(S \& P_{i t} \times A R_{i t}\right)$ & $\begin{array}{c}2.49 \\
\left(6.65^{* * *}\right)\end{array}$ & & & \\
\hline$\left(S \& P_{i t} \times S I Z E_{i t}\right)$ & $\begin{array}{c}0.05 \\
(4.20 * * *)\end{array}$ & & & \\
\hline$\left(S \& P_{i t} \times C F V O L \_A T_{i t}\right)$ & $\begin{array}{c}0.19 \\
(0.80)\end{array}$ & & & \\
\hline$\left(S \& P_{i t} \times O w n_{-}\right.$Conc $\left._{i t}\right)$ & $\begin{array}{l}-1.80 \times 10^{-7} \\
(-2.04 * *)\end{array}$ & & & \\
\hline$\left(S \& P_{i t} \times B I D A S K_{i t}\right)$ & $\begin{array}{c}-0.59 \\
(-0.63)\end{array}$ & & & \\
\hline$\left(S \& P_{i t} \times D P O_{i t}\right)$ & $\begin{array}{c}0.05 \\
\left(2.73^{* * *}\right)\end{array}$ & & & \\
\hline$\left(S \& P_{i t} \times \operatorname{Prox}_{i t}\right)$ & $\begin{array}{c}-2.07 \\
\left(-2.93^{* * *}\right)\end{array}$ & & & \\
\hline
\end{tabular}




\section{Table 10 Cont'd}

Magnitude of Mispricing Regression with S\&P 500 Dummies

\begin{tabular}{|c|c|c|c|c|}
\hline$\left(S \& P_{i t} \times \mid\right.$ Skew $\left._{i t} \mid\right)$ & $\begin{array}{c}-0.01 \\
(-1.64) \\
\end{array}$ & & & \\
\hline $\mathrm{N}$ & 59,591 & 62,352 & 56,140 & 6,212 \\
\hline $\mathrm{R}^{2}$ : within & 0.0238 & 0.0202 & 0.0214 & 0.0302 \\
\hline between & 0.0957 & 0.0873 & 0.0880 & 0.0496 \\
\hline overall & 0.0662 & 0.0596 & 0.0656 & 0.0418 \\
\hline
\end{tabular}




\section{Table 11}

Pearson Correlation Matrix for Independent Variables

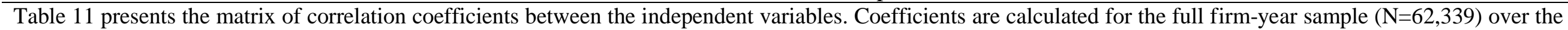

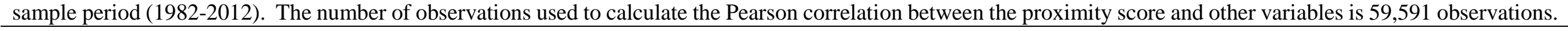

\begin{tabular}{|c|c|c|c|c|c|c|c|c|c|c|c|c|c|c|c|c|c|c|}
\hline & & 1 & 2 & 3 & 4 & 5 & 6 & 7 & 8 & 9 & 10 & 11 & 12 & 13 & 14 & 15 & 16 & 17 \\
\hline$A R_{i t}$ & 1 & 1 & & & & & & & & & & & & & & & & \\
\hline$S_{i z e} i t$ & 2 & -0.54 & 1 & & & & & & & & & & & & & & & \\
\hline$C F V O L \_A T_{i t}$ & 3 & 0.39 & -0.26 & 1 & & & & & & & & & & & & & & \\
\hline Own_Conc $c_{i t}$ & 4 & -0.01 & 0.16 & 0.03 & 1 & & & & & & & & & & & & & \\
\hline$B I D A S K_{i t}$ & 5 & -0.23 & -0.66 & 0.18 & -0.17 & 1 & & & & & & & & & & & & \\
\hline$D P O_{i t}$ & 6 & -0.23 & 0.20 & -0.08 & 0.02 & -0.16 & 1 & & & & & & & & & & & \\
\hline $\operatorname{Prox}_{i t}$ & 7 & 0.35 & -0.47 & -0.11 & 0.01 & -0.19 & 0.09 & 1 & & & & & & & & & & \\
\hline$\left|S k e w_{i t}\right|$ & 8 & -0.23 & -0.13 & 0.14 & 0.03 & 0.04 & -0.03 & -0.08 & 1 & & & & & & & & & \\
\hline$S \& P_{i t}$ & 9 & -0.25 & 0.53 & -0.10 & -0.10 & -0.20 & 0.14 & 0.43 & -0.08 & 1 & & & & & & & & \\
\hline$\left(S \& P_{i t} \times A R_{i t}\right)$ & 10 & -0.16 & 0.45 & -0.08 & -0.08 & -0.17 & 0.11 & 0.37 & -0.04 & 0.89 & 1 & & & & & & & \\
\hline$\left(S \& P_{i t} \times S I Z E_{i t}\right)$ & 11 & -0.25 & 0.54 & -0.10 & -0.03 & -0.20 & 0.15 & 0.43 & -0.08 & 0.99 & 0.88 & 1 & & & & & & \\
\hline$\left(S \& P_{i t} \times C F V O L_{-} A T_{i t}\right)$ & 12 & -0.09 & 0.24 & 0.07 & 0.01 & -0.10 & 0.05 & 0.18 & -0.04 & 0.48 & 0.53 & 0.48 & 1 & & & & & \\
\hline$S \& P_{i t} \times$ Own_Conc $i t$ & 13 & -0.06 & 0.18 & -0.02 & 0.21 & -0.08 & 0.07 & 0.14 & -0.02 & 0.33 & 0.36 & 0.33 & 0.28 & 1 & & & & \\
\hline$\left(S \& P_{i t} \times B I D A S K_{i t}\right)$ & 14 & -0.14 & 0.27 & -0.07 & -0.05 & -0.09 & 0.05 & 0.25 & -0.05 & 0.64 & 0.65 & 0.62 & 0.31 & 0.07 & 1 & & & \\
\hline$\left(S \& P_{i t} \times D P O_{i t}\right)$ & 15 & -0.18 & 0.38 & -0.07 & -0.01 & -0.14 & 0.32 & 0.29 & -0.04 & 0.68 & 0.57 & 0.68 & 0.34 & 0.27 & 0.34 & 1 & & \\
\hline$\left(S \& P_{i t} \times \operatorname{Prox}_{i t}\right)$ & 16 & -0.17 & 0.35 & -0.08 & -0.02 & -0.13 & 0.09 & 0.7 & -0.05 & 0.64 & 0.55 & 0.64 & 0.27 & 0.20 & 0.38 & 0.43 & 1 & \\
\hline$\left(S \& P_{i t} \times\left|S k e w_{i t}\right|\right)$ & 17 & -0.12 & 0.30 & -0.06 & -0.01 & -0.12 & 0.10 & 0.25 & 0.16 & 0.59 & 0.61 & 0.58 & 0.29 & 0.22 & 0.38 & 0.44 & 0.38 & 1 \\
\hline
\end{tabular}

All correlation coefficients are significant at the $1 \%$ significance level. 


\begin{tabular}{|c|c|}
\hline & $\begin{array}{c}\text { Table } 12 \\
\text { Definition of Variables }\end{array}$ \\
\hline Variable & Definition \\
\hline$\left|M i s_{i t}\right|$ & Absolute Value of Mispricing (Rhodes-Kropf et al., 2005) \\
\hline$A R_{i t}$ & Arbitrage risk or idiosyncratic volatility \\
\hline Size $_{i t}$ & Natural log of market value of equity (Pontiff, 1996) \\
\hline CFVOL_AT $i t$ & Cash flow volatility divided by total assets (Lam and Wei, 2011) \\
\hline Own_Conc $i t$ & Ownership concentration (Armstrong et al. 2011) \\
\hline$B I D A S K_{i t}$ & Bid-Ask spread (Lam and Wei, 2011) \\
\hline$D P O_{i t}$ & Dividends payout ratio (Pontiff, 1996) \\
\hline $\operatorname{Prox}_{i t}$ & Proximity score \\
\hline$\left|S_{k e w}\right|$ & Absolute value of skewness \\
\hline$S \& P_{i t}$ & An indicator variable equals one if S\&P 500 member and zero if not \\
\hline$S \& P_{i t} \times X_{i t}$ & $\begin{array}{l}\text { An interaction dummy variable that multiplies each independent variable by } \\
\text { the indicator variable } S \& P_{i t}\end{array}$ \\
\hline
\end{tabular}


APPENDIX

SOLUTION TO PONTIFF (2006) OPTIMIZATION PROBLEM 
The return of the hedge position is given by:

(1) $r_{i}=\alpha_{i}+r_{f}+e_{i}$

The hedge position has no market risk and exposed to only idiosyncratic risk. Therefore, the variance of the hedge portfolio is given by:

(2) $\sigma_{p}^{2}=\sigma_{m}^{2} x_{m}^{2}+\sum_{i=1}^{n} \sigma_{i}^{2} x_{i}^{2}$

The arbitrageur's utility function is given by:

(3) $U=x_{f} r_{f}+x_{m} E\left(r_{m}\right)+\sum_{i=1}^{n}\left(\alpha_{i}+r_{f}\right) x_{i}-\frac{\lambda}{2} \sigma_{p}^{2}$

In order to maximize utility, the arbitrageur will allocate his funds on the three assets and the sum of weights is equal to one. The optimization problem becomes:

(4) $\underset{x_{f}, x_{m}, x_{i}}{\operatorname{Max}} x_{f} r_{f}+x_{m} E\left(r_{m}\right)+\sum_{i=1}^{n}\left(\alpha_{i}+r_{f}\right) x_{i}-\frac{\lambda}{2} \sigma_{p}^{2}$

$$
\text { s.t } x_{f}+x_{m}+\sum_{i=1}^{n} x_{i}=1
$$

(5) $\mathcal{L}=x_{f} r_{f}+x_{m} E\left(r_{m}\right)+\sum_{i=1}^{n}\left(\alpha_{i}+r_{f}\right) x_{i}-\frac{\lambda}{2}\left(\sigma_{m}^{2} x_{m}^{2}+\sum_{i=1}^{n} \sigma_{i}^{2} x_{i}^{2}\right)+\varphi\left(x_{f}+x_{m}+\sum_{i=1}^{n} x_{i}-1\right)$

\section{F.O.Cs}

(6) $\frac{\partial \mathcal{L}}{\partial x_{f}}=r_{f}+\varphi=0$

(7) $\frac{\partial \mathcal{L}}{\partial x_{m}}=E\left(r_{m}\right)-\lambda \sigma_{m}^{2} x_{m}+\varphi=0$ 
(8) $\frac{\partial \mathcal{L}}{\partial x_{i}}=\sum_{i=1}^{n}\left(\alpha_{i}+r_{f}\right)-\lambda \sum_{i=1}^{n} \sigma_{i}^{2} x_{i}+\sum_{i=1}^{n} \varphi=0$

(9) $\frac{\partial \mathcal{L}}{\partial \varphi}=x_{f}+x_{m}+\sum_{i=1}^{n} x_{i}-1=0$

From equation (6):

(10) $\varphi=-r_{f}$

Substitute (10) in (7) and solve for $x_{m}$, we get:

(10) $\frac{\partial \mathcal{L}}{\partial x_{m}}=E\left(r_{m}\right)-\lambda \sigma_{m}^{2} x_{m}-r_{f}=0$

(11) $x_{m}=\frac{\left(E\left(r_{m}\right)-r_{f}\right)}{\lambda \sigma_{m}^{2}}$

Substitute (10) in (8) and solve for $x_{i}$, we get:

(11) $\frac{\partial \mathcal{L}}{\partial x_{i}}=\sum_{i=1}^{n}\left(\alpha_{i}+r_{f}\right)-\lambda \sum_{i=1}^{n} \sigma_{i}^{2} x_{i}-\sum_{i=1}^{n} r_{f}=0$

(12) $x_{i}=\left(\frac{\alpha_{i}}{\lambda \sigma_{i}^{2}}\right)$ 


\section{References}

Admati, A. R., \& Paul, P. (1988). A Theory of Intraday Patterns: Volume and Price Variability. The Review of Financial Studies, 3-40.

Adrian, T., \& Rosenberg, J. (2008). Stock Returns and Volatility: Pricing the Short-Run and Long-Run Components of Market Risk. The Journal of Finance, 2997-3030.

Ali, A., Hwang, L.-S., \& Trombley, M. A. (2003). Arbitrage Risk and the Book-to Market Anomaly. Journal of Financial Economics, 322-373.

Alzahrani, M., \& Ramesh, R. P. (2014). Managerial Behavior and the Link between Stock Mispricing and Corporate Investments: Evidence from Market-to-Book Ratio Decomposition. The Financial Review, 89-116.

Amihud, Y., \& Mendelson, H. (1980). Dealership Market: Market-Making with Inventory. Journal of Financial Economics, 31-53.

Amihud, Y., \& Mendelson, H. (1986). Asset Pricing and the Bid-Ask Spread. Journal of Financial Economics, 223-249.

Armstrong, C. S., Core, J. E., Taylor, D. J., \& Verrecchia, R. E. (2011). When Does Information Asymmetry Affect the Cost of Capital. Journal of Accounting Research, 1-40.

Baker, M., \& Stein, J. C. (2004). Market Liquidity as Sentiment Indicator. Journal of Financial Markets, 271-299.

Barberis, N., \& Shleifer, A. (2003). Sytle Investing. Journal of Financial Economics, 161-199.

Bartram, S. M., Brown, G. W., \& Conrad, J. (2011). The Effects of Derivatives on Firm Risk and Value. Journal of Financial and Quantitative Analysis, 967-999.

Bartram, S. M., Brown, G., \& Stula, R. M. (2012). Why Are U.S. Stocks More Volatile? The Journal of Finance, 1329-1370.

Basak, S., \& Croitoru, B. (2006). On the Role of Arbitrageurs in Rational Markets. Journal of Financial Economics, 143-173.

Beneish, M. D., \& Whaley, R. E. (1996). An Anatomy of the "S\&P Game": The Effect of Changing the Rules. The Journal of Finance, 1909-1930.

Black, F. (1986). Noise. The Journal of Finance, 529-543.

Cai, J. (2007). What's in the News? Information Content of S\&P 500 Additions. Financial Management, 113-124.

Chakrabarti, R., Huang, W., Jayaraman, N., \& Lee, J. (2005). Price and Volume Effects of Changes in MSCI-Nature and Causes. Journal of Banking and Finance, 1237-1264.

Chang, X., Tam, L. H., Tan, T. J., \& Wong, G. (2007). The Real Impact of Stock Market Mispricing-Evidence from Australia. Pacific-Basin Finance Journal, 388-408. 
Chen, H., Noronha, G., \& Singal, V. (2004). The Price Response to S\&P 500 Index Additions and Deletions: Evidence of Asymmetry and a New Explanation. The Journal of Finance, 1901-1929.

Copeland, T. E., \& Galai, D. (1983). Information Effects on the Bid-Ask Spread. The Journal of Finance, 1457-1469.

Danthine, J. (1978). Information, Future Prices, and Stabilizing Speculation. Journal of Economic Theory, 79-98.

Demsetz, H. (1968). The Cost of Transacting. The Quarterly Journal of Economics, 33-53.

Denis, D. K., McConnel, J. J., Ovtchinnikov, A. V., \& Yu, Y. (2003). S\&P 500 Index Additions and Earnings Expectations. The Journal of Finance, 1821-1840.

Dhillon, U., \& Johnson, H. (1991). Changes in the Standard and Poor's 500 List. The Journal of Business, 75-85.

Doukas, J. A., Kim, C., \& Pantzalis, C. (2010). Arbitrage Risk and Stock Mispricing. Journal of Financial and Quantitative Analysis, 907-934.

Easley, D., \& O'Hara, M. (2010). Microstructure and Ambiguity. The Journal of Finance, 18171846.

Elliott, W. B., \& Warr, R. S. (2003). Price Pressure on the NYSE and NASDAQ: Evidence from S\&P 500 Index Changes. Financial Management, 85-99.

Erwin, G. R., \& Miller, J. M. (1998). The Liquidity Effects Associated with Addition of a Stock to the S\&P 500 Index: Evidence from bid/ask Spreads. The Financial Review, 131-146.

Fama, E. F. (1970). Efficient Capital Markets: A Review of Theory and Empirical Work. The Journal of Finance, 383-417.

Fama, E. F., \& French, K. R. (1992). The Cross Section of Expected Stock Returns. The Journal of Finance, 427-465.

Fama, E. F., \& French, K. R. (1993). Common Risk Factors in the Returns on Stocks and Bonds. Journal of Financial Economics, 3-56.

Fama, E. F., \& French, K. R. (1996). Multifactor Explanation of Asset Pricing Anomalies. The Journal of Finance, 55-84.

Frankel, R., \& Lee, C. M. (1998). Accounting Valuation, Market Expectation, and CrossSectional Stock Returns. Journal of Accounting and Economics, 283-319.

Friedman, M. (1953). Essays in Positive Economics. Chicago: University of Chicago Press.

Garman, M. B., \& Ohlson, J. A. (1981). Valuation of Risky Assets in Arbitrage-Free Economies with Transaction Costs. Journal of Financial Economics, 271-280. 
Glosten, L. R., \& Milgrom, P. R. (1985). Bid, Ask and Transaction Prices in a Specialist Market Market with Heterogeneously Informed Traders. Journal of Financial Economics, 71100.

Goetzmann, W. N., \& Garry, M. (1986). Does Delisting from the S\&P 500 Affect Stock Price? Financial Analysts Journal, 64-69.

Grossman, S. (1988). An Analysis of the Implications for Stock and Futures Price Volatility of Program Trading and Dynamic Hedging Strategies. Journal of Business, 275-298.

Grossman, S. J., \& Stiglitz, J. E. (1980). On the Impossibility of Informationally Efficient Markets. The American Economic Review , 393-408.

Grundy, B. D., \& Martin, J. S. (2001). Understanding the Nature of the Risks and the Source of the Rewards to Momentum Investing. The Review of Financial Studies, 29-78.

Harris, L., \& Gurel, E. (1986). Price and Volume Effects Associated with Changes in the S\&P 500 List: New Evidence for the Existence of Price Pressure. The Journal of Finance, 815829.

Hausman, J. A. (1978). Specification Tests in Econometrics. Econometrica, 1251-1271.

Heckman , J., Ichimura, H., \& Todd, P. (1998). Matching as an Econometric Evaluation Estimator. Review of Economic Studies, 261-294.

Heckman, J., Ichimura, H., \& Todd, P. (1997). Matching as an Econometric Evaluation Estimator: Evidence from Evaluating a Job Training Program. Review of Economic Studies, 605-654.

Hedge, S. P., \& McDermott, J. B. (2003). The Liquidity Effects of Revisions to the S\&P 500 Index: and Empirical Analysis. Journal of Financial Markets, 413-459.

Hertzel, M. G., \& Li, Z. (2010). Behavioral and Rational Explanations of Stock Price Performence around SEOs: Evidence from a Decomposition of Market-to-Book Ratios. Journal of Financial and Quantitative Analysis, 935-958.

Jain, P. C. (1987). The Effect $\mathrm{n}$ Stock Price of Inclusion in or Exclusion from the S\&P 500. Financial Analysts Journal, 58-65.

Kaul, A., Mehorta, V., \& Morck, R. (2000). Demand Curves for Stocks Do Slope Down: New Evidence from and Index Weights Adjustment. The Journal of Financeq, 893-912.

Keim, D. B., \& Madhavan, A. (1998). The Cost of Institutional Equity Trades. Financial Analysts Journal, 50-69.

Kraus, A., \& Stoll, H. R. (1972). Price Impact of Block Trading on the New York Stock Exchange. The Journal of Finance, 569-588.

Kyle, A. S. (1985). Continous Auctions and Insider Trading. Econometrica, 1315-1335. 
Lam, F. E., \& Wei, K. J. (2011). Limits-to-Arbitrage, Investment Frictions, and the Asset Growth Anomaly. Journal of Financial Economics, 127-149.

Lin, C.-I. (2007). Changes in Trading Volume and Return Volatility Associated with S\&P 500 Index and Deletions. Unpublished Dissertation.

Lin, J. B., Pantzalis, C., \& Park, J. C. (2010). Corporate Hedging Policy and Equity Mispricing. The Financial Review, 803-824.

Lindenberg, E. B., \& Ross, S. A. (1981). Tobin's q Ration and Industrial Organization. Journal of Business, 1-32.

Liu, J., \& Longstaff, F. A. (2004). Losing Money on Aribtrage: Optimal Dynamic Portfolio Choice in Markets with Arbitrage Opportunities. The Review of Financial Studies, 611641.

Lo, A. W., \& Mackinlay, A. C. (1990). When are Contrarian Profits Due to Stock Market Overreaction? The Review of Financial Studies, 175-205.

Loughran, T., \& Ritter, J. R. (2000). Uniformly Least Powerful Tests of Market Efficiency. Journal of Financial Economics, 361-389.

Lynch, A. W., \& Mendenhall, R. R. (1997). New Evidence on Stock Price Effects Associated with Changes in the S\&P 500 Index. The Journal of Business, 351-383.

Markowitz, H. (1952). Portfolio Selection. The Journal of Finance, 77-91.

Mashruwala, C., Rajgopal, S., \& Shevlin, T. (2006). Why is the Accrual Anomaly not Arbitraged Away? The Role of Idiosyncratic Risk and Transaction Costs. Journal of Accounting and Economics, 3-33.

McLean, R. D. (2010). Idiosyncratic Risk, Long-Term Reversal, and Momentum. Journal of Financial and Quantitative Analysis, 883-906.

Mendenhall, R. R. (2004). Arbitrage Risk and Post-Earnings-Announcement Drift. The Journal of Business, 875-894.

Merton, R. C. (1987). Presedential Address: A Simple Model of Capital Market Equilibrium with Incomplete Information. The Journal of Finance, 483-510.

Mitchell, M., Pulvino, T., \& Stafford, E. (2002). Limited Arbitrage in Equity Markets. The Journal of Finance, 551-584.

Morck, R., \& Yang, F. (2001). The Mysterious Grwoing Value of S\&P 500 Membership. NBER Working Paper.

Morck, R., Shleifer, A., \& Vishny, R. W. (1990). The Stock Market and Investment: In the Market a Sideshow. Brooking Papers on Economic Activity, 2, 157-215. 
Ohlson, J. A. (1995). Earnings, Book Values, and Dividends in Equity Valuation. Contemporary Accounting Research, 661-687.

Pericoli, M., \& Sbracia, M. (2003). A Primer on Financial Contagion. Journal of Economic Surveys, 571-608.

Pontiff, J. (1996). Costly Arbitrage: Evidence From Closed-End Funds. Quarterly Journal of Economics, 1135-1151.

Pontiff, J. (2006). Costly Arbitrage and the Myth of Idiosyncratic Risk. Journal of Accounting and Economics, 35-52.

Pruitt, S. W., \& Wei, K. J. (1989). Institutional Ownership and Changes in the S\&P 500. The Journal of Finance, 509-513.

Rhodes-Kropf, M., \& Viswantan, S. (2004). Market Valuation and Merger Waves. The Journal of Finance, 2685-2718.

Rhodes-Kropf, M., Robinson, D. T., \& Viswanthan, S. (2005). Valuation Waves and Merger Activity: The Empirical Evidence. Journal of Fianancial Economics, 561-603.

Ritter, J. R. (1991). The Long-Run Performence of Initial Public Offerings. The Journal of Finance, 3-27.

Rosenbaum, P., \& Rubin, D. (1983). The Central Role of the Propensity Score in Observational Studies for Casual Effects. Biometrika, 41-55.

Ross, S. A. (1976). The Arbitrage Theory of Capital Asset Pricing. Journal of Financial Economics, 341-360.

Sadka, R., \& Scherbina, A. (2007). Analyst Disagreement, Mispricing, and Liquidity. The Journal of Finance, 2367-2403.

Satterthwaite, F. W. (1946). An Aproximate Distribution of Estimates of Variance Components. Biometric Bulletin, 110-114.

Scholes, M. S. (1972). The Market for Securities: Substitution Versus Price Pressure and the Effects of Information on Share Prices. The Journal of Business, 179-211.

Sharpe, W. F. (1964). Capital Asset Prices: A Theory of Market Equilibrium Under Conditions of Risk. The Journal of Finance, 425-442.

Sharpe, W., \& Alexander, G. (1990). Investments, 4th edition. New Jersey: Prentice Hall, Englewood Cliffs.

Shleifer , A., \& Summers, L. H. (1990). The Noise Trader Approach to Finance. The Journal of Economic Perspective, 19-33.

Shleifer, A. (1986). Do Demand Curves for Stocks Slope Down? The Journal of Finance, 579590. 
Shleifer, A., \& Vishny, R. W. (1997). The Limits of Arbitrage. The Journal of Finance, 35-55.

Sloan, R. G. (1996). Do Stock Prices Fully Reflect Information in Accruals and Cash Flows about Future Earnings? The Accounting Review, 289-315.

Stein, J. C. (2009). Presidential Address: Sophisticated Investors and Market Efficiency. The Journal of Finance, 1517-1548.

Stoll, H. R. (1978). The Supply of Dealer Services in Securities Markets. The Journal of Finance, 1133-1151.

Tobin, J. (1978). Monetary Policies and The Economy: The Transmission Mechanism. Southern Economic Journal, 421-431.

Tuckman, B., \& Vila, J.-L. (1992). Arbitrage With Holding Costs: A Utility Based Approach. The Journal of FInance, 1283-1302.

Vijh, A. (1994). S\&P 500 Trading Strategies and Stock Betas. The Review of Financial Studies, 215-251.

Wurgler, J., \& Zhuravskaya, E. (2002). Does Arbitrage Flatten Demand Curves for Stocks? Journal of Business, 583-608.

Yuan, K. (2005). Asymmetric Price Movements and Borrowing Constraints: A Rational Expectations Equilibrium Model of Crises, Contagion, and Confusion. The Journal of Finance, 379-412.

Zhang, X. F. (2006). Information Uncertainty and Stock Returns. Journal of Finance, 105-136.

Zhao, Z. (2004). Using Matching to Estimate Treatment Effects: Data Requirements, Matching Metrics, and Monte Carlo Evidence. Review of Economics and Statistics, 91-107. 